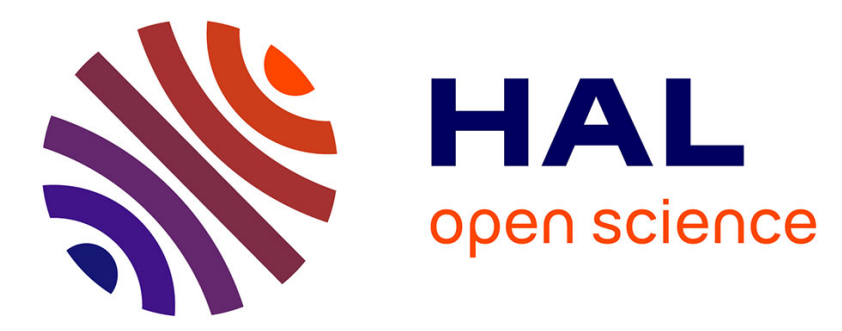

\title{
Molecular dynamics simulations of anion exclusion in clay interlayer nanopores.
}

Christophe Tournassat, Ian C. Bourg, Michael Holmboe, Garrison Sposito, Carl I. Steefel

\section{- To cite this version:}

Christophe Tournassat, Ian C. Bourg, Michael Holmboe, Garrison Sposito, Carl I. Steefel. Molecular dynamics simulations of anion exclusion in clay interlayer nanopores.. Clays and Clay Minerals, 2016, 4, pp.374-388. 10.1346/CCMN.2016.0640403 . insu-01406301

\section{HAL Id: insu-01406301 https://hal-insu.archives-ouvertes.fr/insu-01406301}

Submitted on 11 May 2017

HAL is a multi-disciplinary open access archive for the deposit and dissemination of scientific research documents, whether they are published or not. The documents may come from teaching and research institutions in France or abroad, or from public or private research centers.
L'archive ouverte pluridisciplinaire HAL, est destinée au dépôt et à la diffusion de documents scientifiques de niveau recherche, publiés ou non, émanant des établissements d'enseignement et de recherche français ou étrangers, des laboratoires publics ou privés. 
OPEN ACCESS

\title{
MOLECULAR DYNAMICS SIMULATIONS OF ANION EXCLUSION IN CLAY INTERLAYER NANOPORES
}

\author{
Christophe Tournassat ${ }^{1,2}$, Ian C. Bourg $^{2,3}$, Michael Holmboe ${ }^{4}$, Garrison Sposito ${ }^{2,5}$, and \\ CARL I. STEEFEL ${ }^{2}$ \\ ${ }^{1}$ Université d'Orléans - CNRS/INSU - BRGM, UMR 7327 Institut des Sciences de la Terre d'Orléans, 45071 Orléans, France \\ ${ }^{2}$ Earth and Environmental Sciences Division, Lawrence Berkeley National Laboratory, Berkeley, California, USA \\ ${ }^{3}$ Department of Civil and Environmental Engineering and Princeton Environmental Institute, Princeton, New Jersey, USA \\ ${ }^{4}$ Department of Chemistry, Umeå University, Sweden \\ ${ }^{5}$ Department of Environmental Science, Policy and Management, University of California, Berkeley, California, USA
}

\begin{abstract}
The aqueous chemistry of water films confined between clay mineral surfaces remains an important unknown in predictions of radioelement migration from radioactive waste repositories. This issue is particularly important in the case of long-lived anionic radioisotopes $\left({ }^{129} \mathrm{I}^{-},{ }^{99} \mathrm{TcO}_{4}^{-},{ }^{36} \mathrm{Cl}^{-}\right)$which interact with clay minerals primarily by anion exclusion. For example, models of ion migration in clayey media do not agree as to whether anions are completely or partially excluded from clay interlayer nanopores. In the present study, this key issue was addressed for $\mathrm{Cl}^{-}$using $\mathrm{MD}$ simulations for a range of nanopore widths ( 6 to $15 \AA$ ) overlapping the range of average pore widths that exists in engineered clay barriers. The MD simulation results were compared with the predictions of a thermodynamic model (Donnan Equilibrium model) and two pore-scale models based on the Poisson-Boltzmann equation under the assumption that interlayer water behaves as bulk liquid water. The simulations confirmed that anion exclusion from clay interlayers is greater than predicted by the pore-scale models, particularly at the smallest pore size examined. This greater anion exclusion stems from $\mathrm{Cl}^{-}$being more weakly solvated in nano-confined water than it is in bulk liquid water. Anion exclusion predictions based on the PoissonBoltzmann equation were consistent with the MD simulation results, however, if the predictions included an ion closest approach distance to the clay mineral surface on the order of $2.0 \pm 0.8 \AA$. These findings suggest that clay interlayers approach a state of complete anion exclusion (hence, ideal semi-permeable membrane properties) at a pore width of $4.2 \pm 1.5 \AA$.
\end{abstract}

Key Words-Anion Exclusion, Clay, Donnan Equilibrium Model, Interlayer, Molecular Dynamics, Nanopores, Poisson-Boltzmann, Semi-Permeable Membrane.

\section{INTRODUCTION}

How does water confinement in nanopores impact anion exclusion? The answer to this question has important implications for the migration of salts and groundwater through clay-rich rocks (Fritz, 1986; Leroy et al., 2006), the design of engineered nanofluidic systems (Schoch et al., 2008; Bocquet and Charlaix, 2010), the performance of desalination membranes (Richards et al., 2012), and the transport of ions through channels in cell membranes (Nikaido and Rosenberg, 1981; Nikaido, 2003). It also is of importance to highlevel radioactive waste (HLRW) management, where the performance of geologic repositories is determined, in many cases, by the migration of anionic, long-lived fission products $\left({ }^{129} \mathrm{I}^{-},{ }^{99} \mathrm{TcO}_{4}^{-},{ }^{36} \mathrm{Cl}^{-}\right)$through nanoporous clay barriers (Tournassat et al., 2007; Altmann, 2008; Claret et al., 2010; Glaus et al., 2011; Altmann et al., 2012).

At present, extant models of anion adsorption and diffusion in nanoporous clayey media postulate either

* E-mail address of corresponding author: c.tournassat@brgm.fr

DOI: 10.1346/CCMN.2016.0640403 that anions are completely excluded from clay interlayer nanopores (Sposito, 1992; Wersin et al., 2004; Bourg et al., 2008; Churakov and Gimmi, 2011; Tournassat and Appelo, 2011) or that anions are partially excluded from these nanopores in a manner that can be predicted accurately by assuming nanopore water is the same as bulk liquid water, albeit with a lower electrostatic potential imposed by negatively charged clay surfaces (Leroy et al., 2006; Birgersson and Karnland, 2009; Glaus et al., 2013; Tachi et al., 2014). Efforts to test these two competing hypotheses using anion exclusion measurements have been inconclusive because the results of such measurements depend not only on the mechanistic details of anion exclusion in individual nanopores, but also on the pore-size distribution in saturated, compacted clayey media (Tournassat and Appelo, 2011; Tournassat et al., 2016; Tinnacher et al., 2016), which is not yet fully understood (Holmboe et al., 2012).

This paper is published as part of a special issue on the subject of 'Computational Molecular Modeling'. Some of the papers were presented during the 2015 Clay Minerals Society-Euroclay Conference held in Edinburgh, UK. 
Molecular dynamics (MD) simulations offer a way out of this conundrum by directly examining the details of anion exclusion in individual clay interlayer nanopores. However, three recent studies that quantified anion exclusion in clay interlayers by MD simulation have yielded contradictory results: one concluded that interlayer water can be treated as having the same aqueous chemistry as bulk liquid water (Hedström and Karnland, 2012), whereas two others reached the opposite conclusion, that anion exclusion in clay interlayers is much greater than would be expected based on the aqueous chemistry of bulk liquid water (Rotenberg et al., 2007b; Hsiao and Hedström, 2015). Consequently, the correct way in which to account for anion exclusion in macroscopic models of ion migration in clay formations and engineered clay barriers remains uncertain (Muurinen et al., 2007; Birgersson and Karnland, 2009; Appelo et al., 2010; Tournassat and Appelo, 2011). The present study aimed to resolve the differences among previous MD simulations. The MD analysis was carried out using montmorillonite as a prototypical smectite clay mineral. This clay mineral contributes predominantly to the specific surface area and surface charge characteristics of most engineered clay barriers and many soil and sedimentary formations. It is also the most widely examined clay mineral in studies of anion diffusion through engineered clay barriers (Bourg and Tournassat, 2015). While the present study focuses on clay interlayers, the results should be relevant to ion and salt migration in other charged nanopores with pore widths below $2 \mathrm{~nm}$.

\section{THEORETICAL BACKGROUND}

\section{Donnan equilibrium: the thermodynamic view}

The most widely applied thermodynamic model of anion exclusion in clayey media, the Donnan equilibrium (DE) model, relies on two fundamental assumptions (Babcock, 1960): (1) that chemical equilibrium exists between two distinct aqueous phases, a hydrated clay phase and a bulk aqueous solution phase, and (2) that Henry's Law applies at infinite dilution to all of the ions in both phases. The first assumption implies that anions must always be present in the hydrated clay phase at equilibrium, whereas the second one implies that ions in the hydrated clay phase are completely dissociated from the clay portion at infinite dilution. As shown in the Supplemental Materials section (deposited with the Editor in Chief and available at http://www.clays.org/ JOURNAL/JournalDeposits.html), the two assumptions of the DE model yield the following expression for the concentration ratio of the anions in the case of an aqueous $\mathrm{NaCl}$ solution in equilibrium with a hydrated clay (Babcock, 1960, 1963):

$$
\frac{m_{\mathrm{Cl}}^{\text {clay }}}{m_{\mathrm{Cl}}^{\mathrm{soln}}}=\frac{\sqrt{\theta^{2}+4 y^{2}}}{2 y \theta}-\frac{1}{2 y}
$$

where

$$
\theta^{2}=\frac{\gamma_{\mathrm{Cl}}^{\text {clay }} \cdot \gamma_{\mathrm{Na}}^{\text {clay }}}{\gamma_{\mathrm{Cl}}^{\text {sln }} \cdot \gamma_{\mathrm{Na}}^{\text {soln }}}
$$

$m_{i}$ and $\gamma_{i}$ are the molality (mol $\mathrm{kg}^{-1}$ ) and activity coefficient of ion $i$,

$$
y=\frac{m_{\mathrm{Cl}}^{\mathrm{soln}}}{q_{\text {clay }}}
$$

is the ratio of anion charge concentration in aqueous solution to that of the clay anionic charge (both in moles of charge per $\mathrm{kg}$ of water), and the superscripts clay and soln refer to the hydrated clay phase and the bulk aqueous solution phase, respectively. Thus, the anion concentration ratio of the two phases is determined solely by the anion-to-clay charge ratio $y$ and the electrolyte activity coefficient ratio $\theta$. Note that $\theta=1$ if the electrolyte in each phase has the same mean ionic activity coefficient. The left side of Equation 1 may be very small, indicating anion exclusion, or may be larger than 1, indicating positive anion adsorption in the hydrated clay phase, depending on the values of $y$ and $\theta$. (In general, $\theta$ will depend on $y$.) Consequently, the DE model predicts quite generally that, not only are anions always present in clay interlayers, anions can even swarm there under certain circumstances (Babcock, 1960). This prediction, of course, is a direct consequence of the two model assumptions and thus cannot be considered as a theoretical proof of the presence of anions in clay interlayer nanopores in equilibrium with bulk aqueous solution. Moreover, Equation 1 cannot be applied in a predictive manner, because no accurate model of $\gamma_{i}^{\text {clay }}$ exists. Studies of anion exclusion and semi-permeable membrane properties in clayey media have, therefore, routinely used Equation 1 along with the simplifying approximation that $\gamma_{i}^{\text {clay }}=1$ or $\theta=1$ for all ions (Kharaka and Berry, 1973; Fritz, 1986; Keijzer et al., 1999; Sherwood and Craster, 2000; Revil et al., 2011), an approximation that forms the basis of the well known Teorell-Meyer-Sievers model of ion migration in charged semi-permeable membranes (Wang et al., 1995; Schoch et al., 2008). Brownian dynamics calculations, however, strongly suggest that $\theta<1$ for a three-layer hydrate of montmorillonite equilibrated with a $\mathrm{NaCl}$ solution, whereas $\theta \approx 1$ in larger interlayer pores (Jardat et al., 2009).

\section{Gouy-Chapman model: the molecular scale view}

An alternative to thermodynamic modeling of anion exclusion is to describe, at the molecular scale, the structure of the electrical double layer (EDL), i.e. the 
distribution of aqueous ions in the vicinity of a charged surface. The simplest approach derives from the GouyChapman model, which is based on six assumptions: first, that the Poisson equation, which relates the electrostatic potential in a swarm of ions to the net charge density in the swarm, remains physically meaningful on molecular length scales; second, that the surface from which $x$ is measured is a uniform, infinite plane of charge characterized by a surface charge density $\sigma$ (in $\mathrm{C} \mathrm{m}^{-2}$ ); third, that the charged species in the nearby aqueous solution are fully dissociated from the planar surface lying at $x=0$; fourth, that these ions interact among themselves and with the surface exclusively through the coulomb force; fifth, that water can be represented as a uniform continuum characterized solely by the dielectric constant $\varepsilon$; and, finally, that the potential of mean force $W(x)$ is proportional to the mean electrostatic potential, $\psi^{\mathrm{EDL}}(x)$, at a distance $x$ from the charged surface (Sposito, 1984, 2004). Under these assumptions, the Poisson equation can be transformed into the Poisson-Boltzmann (PB) equation of the Gouy-Chapman model:

$$
\begin{aligned}
\frac{d \psi^{\mathrm{EDL}}(x)}{d x^{2}} & =-\frac{F}{\varepsilon \cdot \varepsilon_{0}} \sum_{i} z_{i} c_{i}(x) \\
& =-\frac{F}{\varepsilon \cdot \varepsilon_{0}} \sum_{i} z_{i} c_{i}^{\mathrm{soln}} \exp \left(\frac{z_{i} F \psi^{\mathrm{EDL}}(x)}{\mathrm{R} T}\right)
\end{aligned}
$$

where $F$ is Faraday's constant (96 $\left.485 \mathrm{C} \mathrm{mol}^{-1}\right), R$ is the ideal gas constant $\left(8.314 \mathrm{~J} \mathrm{~mol}^{-1} \mathrm{~K}^{-1}\right), T$ is absolute temperature, $\varepsilon_{0}$ is the permittivity of vacuum $\left(8.845 \times 10^{-12} \mathrm{C} \mathrm{V}^{-1} \mathrm{~m}^{-1}\right), \varepsilon$ is the dielectric constant of water, and $c_{i}$ is the molality of ion $i\left(\mathrm{~mol} \mathrm{dm}{ }^{-3}\right)$. The electrostatic potential $\psi^{\mathrm{EDL}}(x)$ has no thermodynamic significance. In particular, it cannot be substituted for $\psi^{\text {clay }}$ in Equation 1 because it cannot be measured without relying on ad hoc non-thermodynamic concepts and models (Babcock, 1963; Sposito, 1984).

The Gouy-Chapman model is routinely used to describe anion exclusion and migration in clay-water systems and other charged nanoporous media (Smith et al., 2004; Schoch et al., 2008; Cheng and Hendry, 2014). Two specialized forms of the model are widely used. The first, known as the modified Gouy-Chapman (MGC) model, is based on the assumptions listed above along with the additional condition that ions can be modeled as hard spheres and, therefore, have a distance of closest approach $a$ to the clay surface (Sposito, 1992; Kim and Netz, 2006). The MGC model is consistent with experimental data on anion exclusion in dilute clay suspensions if $a \approx 1.8 \AA$ (Sposito, 1992). The second specialized form, known as the mean electrostatic potential (MEP) model, is based on the same assumptions as the Gouy-Chapman model along with the simplifying approximation that $\psi^{\mathrm{EDL}}(x)$ does not vary with distance from the charged surface within the EDL.
This MEP approximation allows Equation 2 to be solved analytically for complex electrolytes or for systems where the diffuse layers on different charged surfaces overlap. As shown in the Supplemental Materials section, the MEP model yields the expression:

$$
\frac{c_{\mathrm{Cl}}^{\overline{\mathrm{EDL}}}}{c_{\mathrm{Cl}}^{\mathrm{soln}}}=\frac{\sqrt{1+4 y^{\prime 2}}}{2 y^{\prime}}-\frac{1}{2 y^{\prime}}
$$

where $c_{\mathrm{Cl}}^{\overline{\mathrm{ELL}}_{\text {is }}}$ the mean chloride concentration in the EDL,

$$
y^{\prime}=\frac{c_{\mathrm{Cl}}^{\mathrm{soln}} F h_{\mathrm{EDL}}}{\sigma},
$$

$\sigma$ is again the surface charge density $\left(\mathrm{C} \mathrm{m}^{-2}\right)$, and $h_{\mathrm{EDL}}$ is the thickness of the region occupied by the EDL (in $\mathrm{m}$ ). A distance of closest approach of ions to the charged surface can be incorporated into the MEP model by substituting $\left(h_{\mathrm{EDL}}-a\right)$ for $h_{\mathrm{EDL}}$, thus defining an "ion-accessible EDL thickness" in Equation 3.

\section{Implications}

Equations 1 and 3 obviously have very similar forms. Because of this similarity, the terms "Donnan model," or "Donnan volume," are sometimes erroneously used to describe the MEP model despite its molecular-scale assumptions (Appelo and Wersin, 2007; Schoch et al., 2008; Birgersson and Karnland, 2009; Tertre et al., 2011; Tournassat et al., 2011; Glaus et al., 2013). The DE model, however, is based on chemical thermodynamics and, therefore, is fundamentally different from the MGC and MEP models, or any other model involving molecular-scale concepts.

Whether a Donnan equilibrium model or a model based on the Poisson-Boltzmann equation is best suited for predicting anion concentrations in clay mineral interlayers cannot be readily answered by comparing model predictions with macroscopic experimental results. Macroscopic data can be fitted to the DE model by adjusting the clay-phase activity coefficients in $\theta$. Since neither the individual activity coefficient values nor the Donnan potential is accessible experimentally, $\theta$ cannot be constrained independently. Similarly, macroscopic anion-exclusion data can be fitted with the MGC or MEP model by adjusting the pore-size distribution or the distance of closest approach of ions to the clay surface (Muurinen et al., 2007; Tournassat and Appelo, 2011; Tournassat et al., 2016). Independent information must, therefore, be sought that can be used to test these modeling approaches. In the following, MD simulations are shown to be insightful in this respect.

\section{MOLECULAR DYNAMICS SIMULATION METHODOLOGY}

Simulations of clay-water systems with three interlayer nanopores in contact with a larger mesopore were 
carried out with the program LAMMPS (Plimpton, 1995). Water molecules were assumed to be rigid according to the SHAKE algorithm (Ryckaert et al., 1977). The clay mineral structure was also assumed to be rigid, as in previous simulations of this type (Rotenberg et al., 2007b; Hedström and Karnland, 2012; Hsiao and Hedström, 2015), but clay $\mathrm{H}$ atoms were allowed to move. Recent MD simulations have shown that the equilibrium distributions of interlayer water and ions (but not their dynamics) are insensitive to the motions of clay atoms (Holmboe and Bourg, 2014). Interatomic interactions were described with the SPC/E model of liquid water (Berendsen et al., 1987), the CLAYFF model of mineral-water interactions (Cygan et al., 2004), and the ion-water interaction parameters of Smith and Dang (1994). Van der Waals interactions between unlike atomic species were derived using the Lorentz-Berthelot combining rules. The CLAYFF model includes Van der Waals and Coulomb interaction parameters for atoms in the bulk clay mineral structure and for certain functional groups on the clay edge surfaces $\left(>\mathrm{Si}-\mathrm{OH},>\mathrm{Al}_{2}-\mathrm{OH}\right)$, but not for other clay mineral edge groups $(>\mathrm{AlOH},>\mathrm{Al}-\mathrm{O}-\mathrm{Si}<)$. For the present study, CLAYFF-like interatomic parameters were derived for edge $>\mathrm{AlOH}$ and $>\mathrm{Al}-\mathrm{O}-\mathrm{Si}<$ groups as described in the Supplemental Materials section.

The cis-vacant structure of montmorillonite was taken from Tsipursky and Drits (1984). Individual clay mineral layers (hereafter referred to as TOT layers) were truncated at the (110) and (110) structural planes in order to create edge surfaces, which were then healed by adding $-\mathrm{OH}$ or $-\mathrm{H}$ groups to under-coordinated edge atoms in order to obtain edge surfaces with zero net proton surface charge (Churakov, 2006). The resulting edge surface structures, which correspond to the AC chains of White and Zelazny (1988), are thought to be the most stable or one of the most stable smectite edge structures (White and Zelazny, 1988; Bickmore et al., 2003; Churakov, 2006; Liu et al., 2014; Newton and Sposito, 2015; Newton et al., 2016). Each TOT layer had a thickness of $\sim 10 \AA$ (ambiguities associated with the definition of the TOT layer thickness are discussed below), a finite length of $45.7 \AA$ in the direction normal to the edge surfaces, and a width of $63.4 \AA$ (effectively an infinite width, because of the periodic boundary conditions of the simulation cell). Each simulation cell contained three TOT layers, three interlayer nanopores, and a larger mesopore (Figure 1). The cell had an initial length of $90 \AA$ in the direction normal to the clay mineral edges (before pressure equilibration), a width of $63.4 \AA$, and a height of $46.8 \AA, 56.7 \AA$, or $76.5 \AA$ in the direction normal to the clay basal surfaces for simulations of the two-, three-, and five-layer hydrates (referred to hereafter as $2 \mathrm{WL}, 3 \mathrm{WL}$, and $5 \mathrm{WL}$ systems, respectively). Isomorphic substitutions of $\mathrm{Mg}$ for $\mathrm{Al}$ were randomly distributed on cis octahedral sites. In order to minimize uncertainties associated with the parameterization of edge surface sites, isomorphic substitutions were not allowed to occur near the edge surfaces. The mean number of isomorphic substitutions (108 substitutions

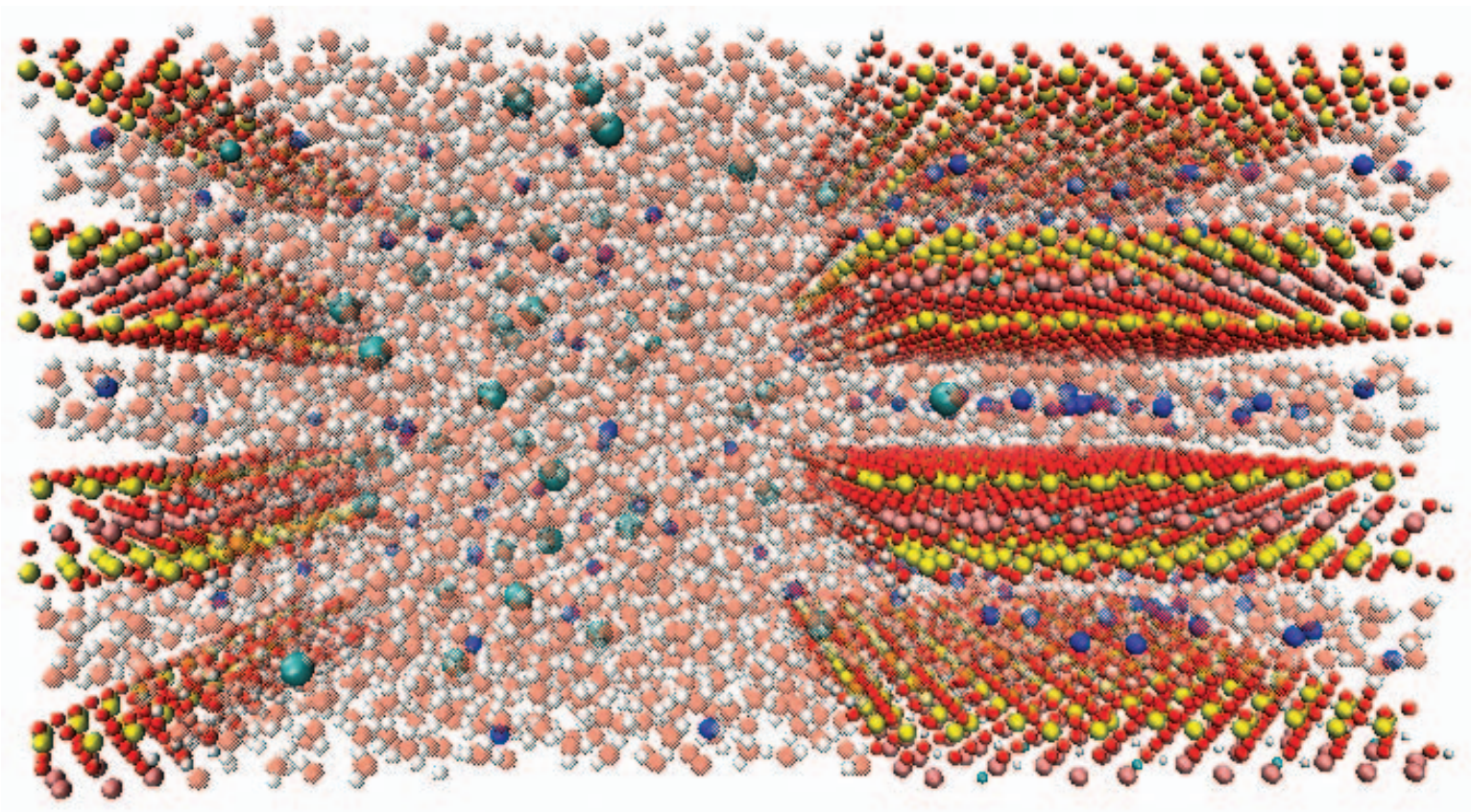

Figure 1. Snapshot of the simulated 2WL system with layer edges bordering a mesopore, highlighting the difference in concentrations of $\mathrm{Na}$ (small dark blue spheres) and $\mathrm{Cl}$ (large light blue spheres) atoms in the interlayer nanopores and in the mesopore. Water $\mathrm{O}$ and $\mathrm{H}$ atoms are shaded. The system is periodic in all directions. 
randomly distributed between the three TOT layers) was selected in order to obtain a mean basal surface charge density near $-0.1 \mathrm{C} \mathrm{m}^{-2}$, a value typical of montmorillonite (Sposito, 1984).

Each simulation cell included $148 \mathrm{Na}^{+}$ions and $40 \mathrm{Cl}^{-}$ions as required to balance the negative surface charge of the TOT layers and establish a $\mathrm{NaCl}$ concentration in the mesopore of $\sim 0.5 \mathrm{~mol} \mathrm{dm}{ }^{-3}$, $\sim 0.4 \mathrm{~mol} \mathrm{dm}^{-3}$, or $\sim 0.3 \mathrm{~mol} \mathrm{dm}^{-3}$ in the $2 \mathrm{WL}, 3 \mathrm{WL}$, and $5 \mathrm{WL}$ systems, respectively. The $\mathrm{NaCl}$ concentration in the mesopore was chosen such that the MEP model calculations of Hedström and Karnland (2012) (based on Equation 2, with $h_{\mathrm{EDL}}$ equal to one-half the width of a clay interlayer nanopore and with a closest approach distance of $a=0$ ) would predict one $\mathrm{Cl}^{-}$ion in each interlayer nanopore, on average, during the entire simulation. Previous calculations have indicated that, at the ionic strengths examined in the present study, the region where the electrostatic potential spills over between the nanopore and mesopore extends $\sim 1 \mathrm{~nm}$ from the clay mineral edges into the interlayer nanopores and into the mesopore (Kraepiel et al., 1999; Jardat et al., 2009). These simulated systems should, therefore, be sufficiently large to contain interlayer and mesopore regions that are not influenced by proximity to the clay edge surfaces.

As in the simulations of Hedström and Karnland (2012), a single $\mathrm{Cl}$ ion (hereafter denoted $\mathrm{Cl}_{\text {int }}$ ) was initially placed in the center of each interlayer nanopore. The three $\mathrm{Cl}_{\text {int }}$ ions were held fixed during equilibration, then allowed to move freely during the simulation. Production runs were carried out in the NVT ensemble (constant composition, volume, and temperature) at $T=$ $350 \mathrm{~K}$ with a 1 fs time step. Simulation runs were preceded by $0.5 \mathrm{~ns}$ of equilibration in the NVT ensemble, $0.5 \mathrm{~ns}$ of equilibration in an $N P_{y} T$ ensemble (constant composition, stress in the direction normal to the edge surfaces, and temperature) at $P_{y}=1$ bar and $T=350 \mathrm{~K}$, and another 2 ns of equilibration in the $N V T$ ensemble. Electrostatic and dispersion interactions beyond $15 \AA$ were computed by the Ewald sum method during part of the simulation (22 ns, $17 \mathrm{~ns}$, and $15 \mathrm{~ns}$ for the $2 \mathrm{WL}$, $3 \mathrm{WL}$, and $5 \mathrm{WL}$ systems, respectively), then by the similarly accurate particle-particle particle-mesh (PPPM) method (Eastwood et al., 1980; Isele-Holder et al., 2012) during the remaining part of a simulation (up to $53 \mathrm{~ns}, 40 \mathrm{~ns}$, and $38 \mathrm{~ns}$ for the $2 \mathrm{WL}, 3 \mathrm{WL}$, and $5 \mathrm{WL}$ systems, respectively).

The contributions of various electrostatic interactions to the potential energy of all $\mathrm{Cl}^{-}$and $\mathrm{Na}^{+}$ions were calculated using LAMMPS. The contributions of electrostatic interactions with water molecules, clay mineral atoms, and other ions $\left(\mathrm{Na}^{+}, \mathrm{Cl}^{-}\right)$to the total per-atom potential energy of $\mathrm{Na}^{+}$and $\mathrm{Cl}^{-}$ions were calculated by canceling the charges of all water atoms, then of all water and montmorillonite atoms during different reexaminations of a trajectory. For the last calculation, where only $\mathrm{Na}^{+}$and $\mathrm{Cl}^{-}$mutual electrostatic interactions were calculated, the system was not neutral (an excess of $\mathrm{Na}^{+}$was present due to the TOT layer surface charge) and the computation of a relevant total electrostatic energy (including pairwise and k-space energy contributions) was not possible. Consequently, only pairwise energies were computed with a cutoff at $25 \AA$.

\section{RESULTS}

\section{$\mathrm{Cl}^{-}$access to the interlayer}

All $\mathrm{Cl}_{\text {int }}$ atoms left the $2 \mathrm{WL}$ and $3 \mathrm{WL}$ interlayer space within three nanoseconds of simulation. During the same period of time, $\mathrm{Cl}^{-}$ions from the mesopore entered the $3 \mathrm{WL}$ nanopores but did not enter the $2 \mathrm{WL}$ nanopores. In the $5 \mathrm{WL}$ system, not all of $\mathrm{Cl}_{\text {int }}$ atoms left the interlayer space within the same period of time. According to the concentration maps that were computed after 3 ns of simulation, $\mathrm{Cl}^{-}$has access to $3 \mathrm{WL}$ and $5 \mathrm{WL}$ interlayers, but not to $2 \mathrm{WL}$ interlayers (Figure 2). Note that in the $2 \mathrm{WL}$ system, the reported $\mathrm{Cl}^{-}$concentration in the interlayer space is truly zero, not simply a low value that is unresolved by the color concentration scale.

\section{$\mathrm{Na}, \mathrm{Cl}$, and water distribution profiles in the interlayer nanopores}

Concentration profiles from molecular dynamics. Total $\mathrm{Cl}^{-}$and $\mathrm{Na}^{+}$concentration profiles and water density profiles (Figure 3) were computed with a spatial resolution of $0.5 \AA$ on the $z$-axis in the $y \quad[65-85 \AA]$ interval, i.e. in the middle of the interlayer nanopores. The calculated water-density profiles correspond to the concentration of $\mathrm{O}$ atoms in water molecules multiplied by the mass of one mole of water. The $\mathrm{Na}^{+}$ions were concentrated in a single peak at the center of the $2 \mathrm{WL}$ interlayer space, while two main peaks were present in the $3 \mathrm{WL}$ and $5 \mathrm{WL}$ interlayer spaces (Figure 3) in agreement with previous MD and Monte Carlo (MC) simulations of Na-montmorillonite with structural charge arising from isomorphic substitutions in the octahedral sheet (Marry et al., 2002; Tambach et al., 2004; Holmboe and Bourg, 2014). The $\mathrm{Na}$ density maxima were located at a distance of $\sim 4.5 \AA$ from the siloxane surface $\mathrm{O}$ atoms of the TOT layer and separated from the TOT layer by a hydration layer characterized by a water $\mathrm{O}$ density peak. Peak positions were consistent with previous studies of clay mineral interlayer nanopores and larger pores (Marry et al., 2002; Tournassat et al., 2009; Bourg and Sposito, 2011). The height of the $\mathrm{Na}$ density peaks increased with the number of isomorphic substitutions in the nearby TOT layer, as expected from charge balance considerations. The height of the main water density peak was correlated, but was not strictly proportional, to that of the $\mathrm{Na}$ peak, indicating that the structure of the interfacial water layer was significantly influenced by both the clay surface and the adsorbed cations. Few $\mathrm{Na}^{+}$ 
Concentration - $\mathrm{Cl}$
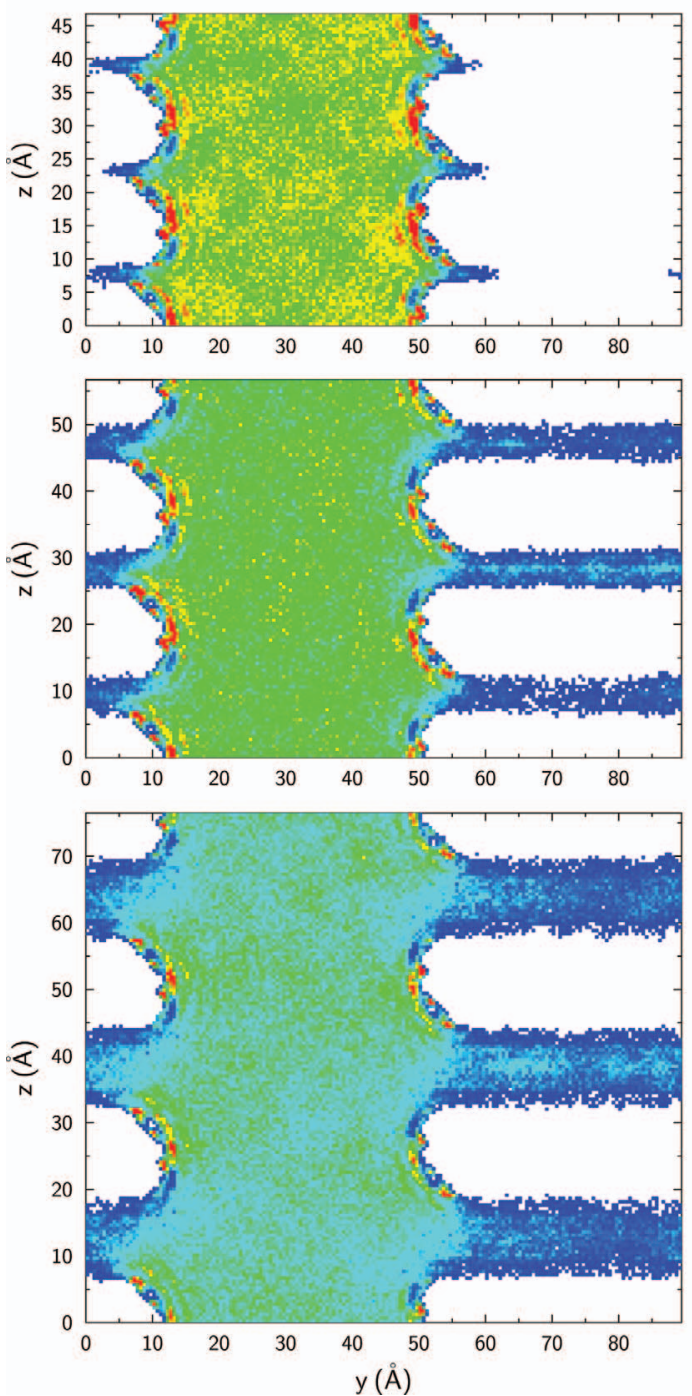

Concentration - $\mathrm{Na}$
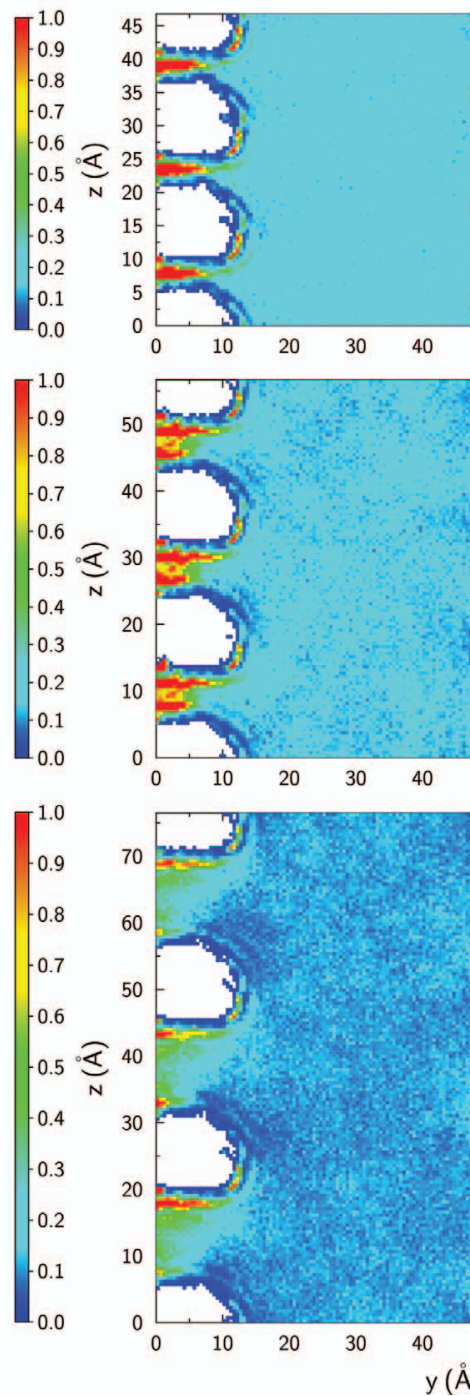
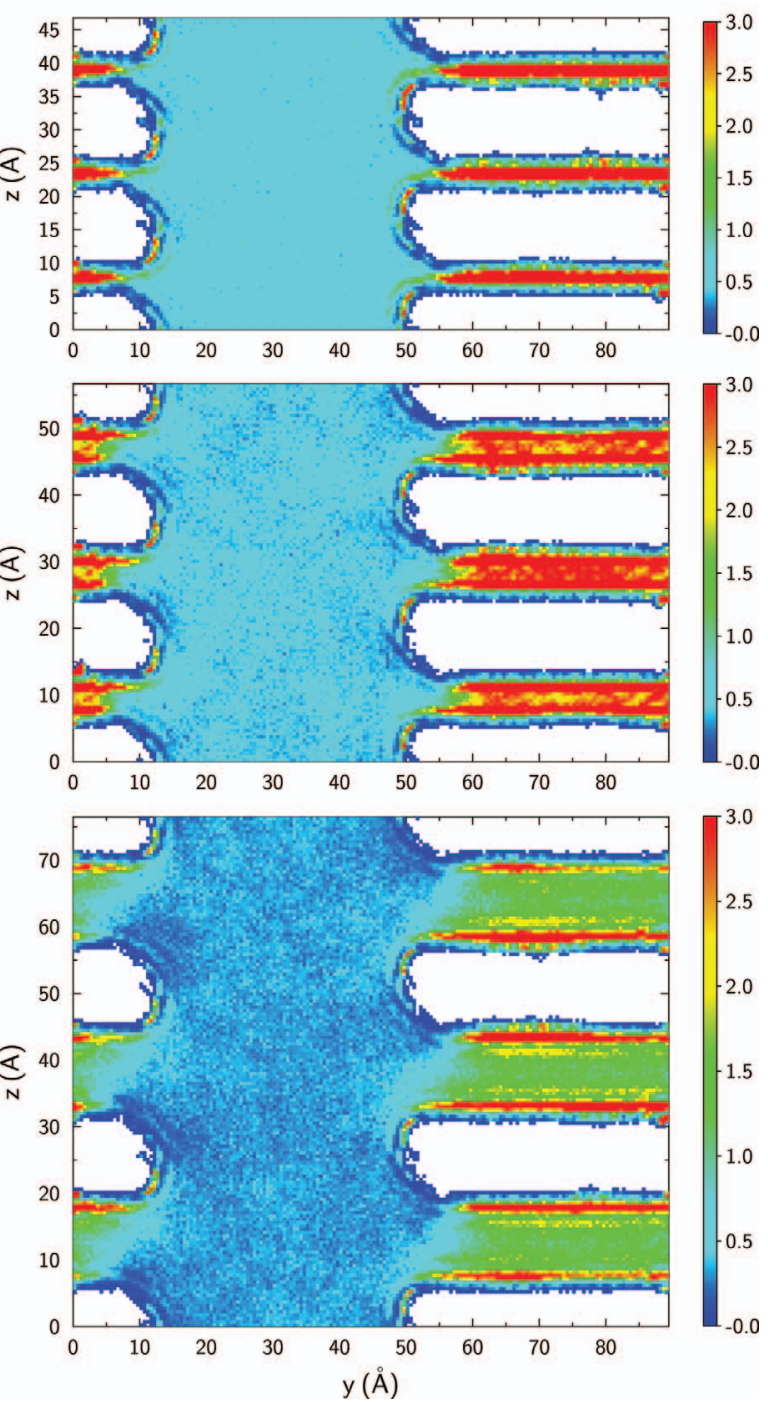

Figure 2. The $\mathrm{Cl}^{-}$(left) and $\mathrm{Na}^{+}$(right) concentration maps in the $2 \mathrm{WL}, 3 \mathrm{WL}$, and $5 \mathrm{WL}$ systems (from top to bottom). The colored concentration scale is in mol dm ${ }^{-3}$. White areas correspond to regions where no $\mathrm{Cl}^{-}$or $\mathrm{Na}^{+}$ions were present during the entire $\mathrm{MD}$ run.

ions were engaged in inner sphere surface complexes. In the case of $\mathrm{Cl}$, density profiles showed significant anion exclusion even at the mid-plane of the nanopores (Figure 3). The distance of closest approach of $\mathrm{Cl}^{-}$to the plane of $\mathrm{O}$ atoms on the basal surface was $~ 3.5 \AA$. This value coincides with the distance of closest approach of $\mathrm{Na}^{+}$ions that were not bound in innersphere surface complexes.

$\mathrm{Na}^{+}$and $\mathrm{Cl}^{-}$mean interlayer concentrations according to MD calculations. At the scale of an individual interlayer nanopore, average concentrations calculated from the MD concentration profiles depend on an arbitrary choice of the boundary between the pore space and the solid phase. The DE model calculations presented in a previous section are based on a molality convention (mol per kilogram of water) while the MGC and MEP model calculations are based on a molarity convention $\left(\mathrm{mol} \mathrm{dm}{ }^{-3}\right)$ with the underlying assumption of a water density of $1 \mathrm{~kg} \mathrm{dm}^{-3}$ (note that the effect of temperature on water density was neglected). Consequently, the location of the clay mineral-water boundary was identified based on the choice that yields an average interlayer water density of $1 \mathrm{~kg} \mathrm{dm}^{-3}$. The resulting effective TOT layer thickness equals $9.78 \pm$ $0.45 \AA$ for all three systems investigated in the present study (Table 1). Accordingly, average interlayer ion densities were calculated based on interlayer nanopore widths of $5.7,9.1$, and $15.6 \AA$ in the 2,3 , and $5 \mathrm{WL}$ systems, respectively (Table 1). 
$3 \mathrm{WL}$
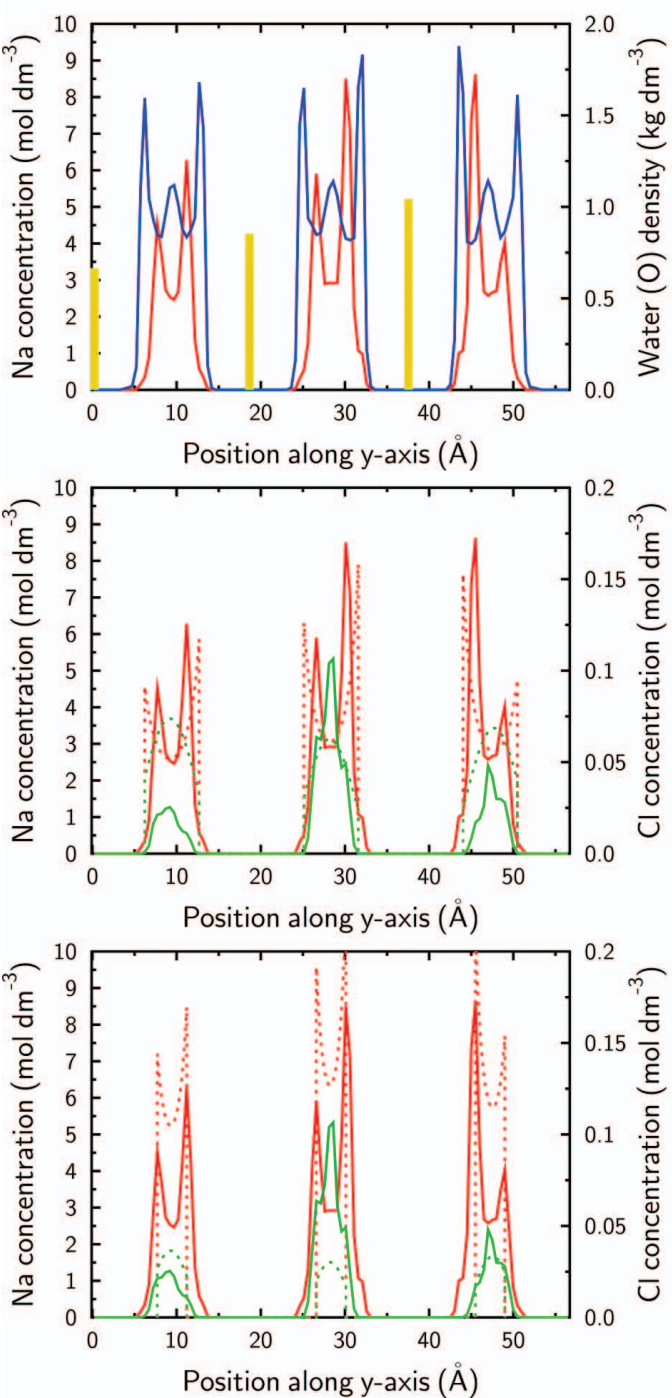

$5 \mathrm{WL}$
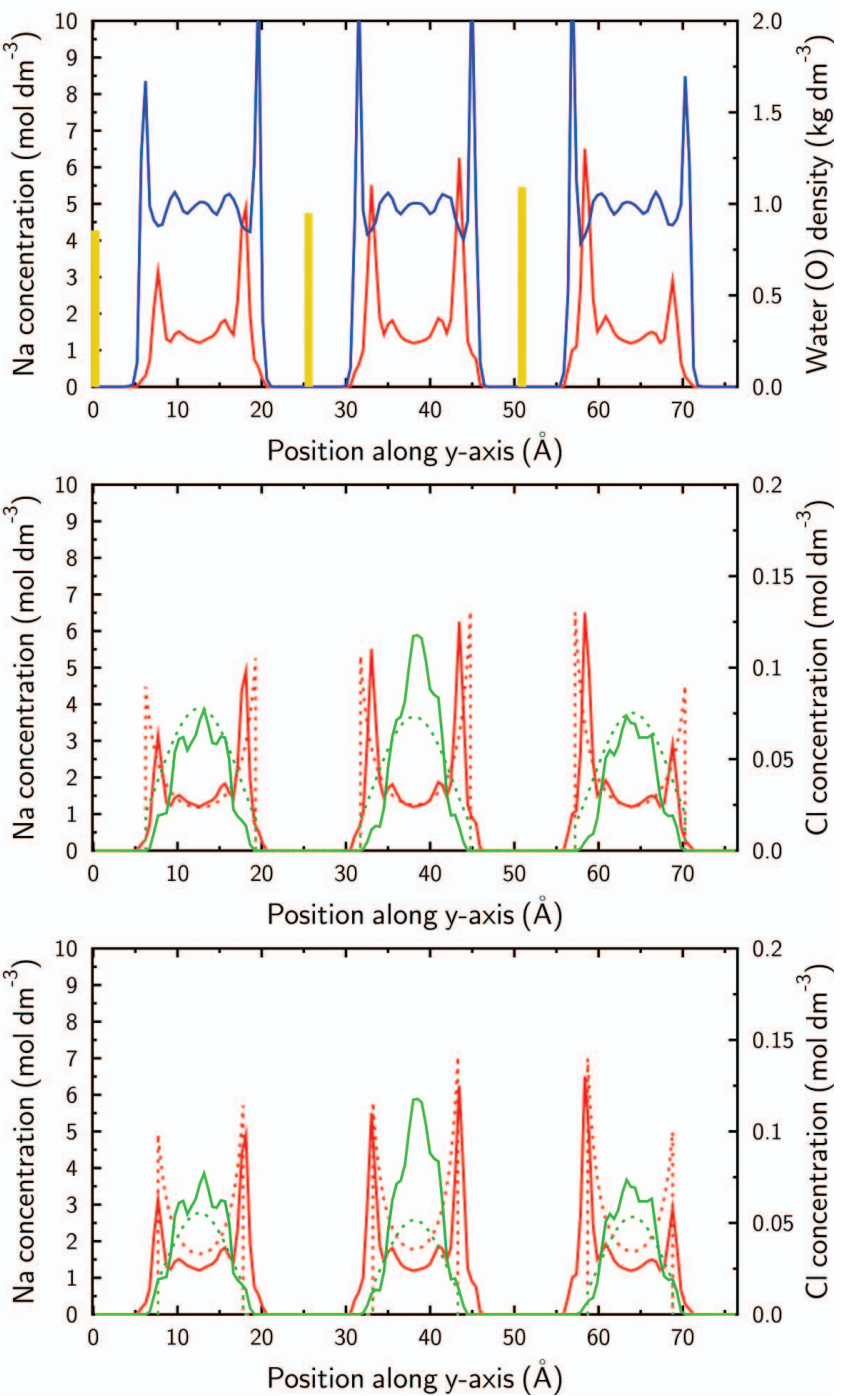

Figure 3. Concentration profiles in the interlayer region $\left(y[65-85 \AA]\right.$ ) for the $3 \mathrm{WL}$ (left) and $5 \mathrm{WL}$ (right) systems. Top: Na ${ }^{+}$ concentration (red) and water density ( $\mathrm{O}$ atoms, blue) profiles; the orange bar indicates the number of $\mathrm{Mg}$ for $\mathrm{Al}$ substitutions in the TOT layer (arbitrary unit). Middle: comparison of $\mathrm{Na}^{+}$(red) and $\mathrm{Cl}^{-}$(green) $\mathrm{MD}$ concentration profiles (plain lines) with the PB prediction (dotted lines) assuming a distance of ion closest approach to the surface of $3.5 \AA$ from the most external oxygen atoms of the TOT layer. Bottom: same calculations but with an ion closest approach distance to the surface corresponding to the maximum $\mathrm{Na}^{+}$concentration peak position.

Table 1. Effective TOT layer thicknesses (in $\AA$ ) as a function of the basal spacing for the $2 \mathrm{WL}, 3 \mathrm{WL}$, and $5 \mathrm{WL}$ systems. The layer thickness that yields an interlayer water density of $1 \mathrm{~kg} \mathrm{dm}^{-3}$ is denoted 'Water density.' The value calculated from the $\mathrm{Cl}^{-}$distance of closest approach to the surface is denoted 'Closest approach.' The value calculated from the location of the $\mathrm{Na}^{+}$density peaks is denoted 'Na peaks.'

\begin{tabular}{lcccc}
\hline & Basal spacing $(\AA)$ & \multicolumn{3}{c}{$\begin{array}{c}\text { Effective TOT layer thickness }(\AA) \\
\text { Closest approach }\end{array}$} \\
\hline 2WL & 15.6 & Water density & Na peaks \\
3WL & 18.9 & 9.56 & 12.45 & 15.6 \\
$5 \mathrm{WL}$ & 25.5 & 9.0 & 12.45 & 15.4 \\
& & & & 15.4 \\
\hline
\end{tabular}


Concentration profiles predicted with the MGC and MEP models. For comparison with the mean interlayer concentrations predicted by MD simulation, interlayer concentrations of $\mathrm{Na}^{+}$and $\mathrm{Cl}^{-}$were calculated using the MGC and MEP models. The MGC model predictions were obtained by solving the PB equation (Equation 2) numerically using the values of $\sigma$ and $c_{i}^{\text {soln }}$ from the MD simulation as input parameters (Table 2). The distance of closest approach of ions to the solid surface was identified based on the MD concentration profiles, using either the location of the 'foot' of the $\mathrm{Na}^{+}$density profiles or the location of the $\mathrm{Na}^{+}$density peak (Figure 3 and Table 1). In the case of the $2 \mathrm{WL}$ system, the second option was not available because only one $\mathrm{Na}^{+}$density peak was present. The MEP model calculations assumed that the EDL filled the entire interlayer pore space and involved the same assumptions as the MGC model regarding the distance of closest approach of ions to the clay mineral surface (Table 2). Predicted $\mathrm{Na}^{+}$and $\mathrm{Cl}^{-}$ density profiles were converted to average concentrations per mass of interlayer water in order to ensure consistency between different results.

\section{Maps of per-atom electrostatic energy}

The per-atom electrostatic energy corresponds to the coulomb energy attributed to each individual $\mathrm{Cl}^{-}\left(\mathrm{Na}^{+}\right)$ ion in the system. For the 2WL system (Figure 4), the computation of the per-atom energy for $\mathrm{Cl}^{-}$in the interlayer space was not possible because chloride did not enter the interlayer space during the simulation. On the other hand, the total per-atom electrostatic energy was the same in the mesopore as in the interlayer in the $3 \mathrm{WL}$ and 5WL systems (Figures 5 and 6). The most remarkable outcome of this calculation is that, in the $3 \mathrm{WL}$ and $5 \mathrm{WL}$ systems, the electrostatic energy arising from $\mathrm{Cl}^{-}$solvation was much higher (less favorable interaction) in interlayer nanopores than in the mesopore. The opposite effect was not observed in the case of $\mathrm{Na}^{+}$; electrostatic interaction of $\mathrm{Na}^{+}$ions with water molecules was approximately equally favorable in the interlayer nanopores as in the mesopores. A similar asymmetry in $\mathrm{Na}^{+}$and $\mathrm{Cl}^{-}$solvation energies has been observed in model polar nanopores and ascribed to hindered orientations of confined water molecules hydrating $\mathrm{Cl}^{-}$in nanopores (Crozier et al., 2001). As expected, interactions with other ions in the interlayers were attractive in the case of $\mathrm{Cl}^{-}$and repulsive in the case of $\mathrm{Na}^{+}$(lower row in Figures 4, 5, and 6).

\section{DISCUSSION}

\section{$2 W L$ hydrate}

In the case of the $2 \mathrm{WL}$ hydrate, no $\mathrm{Cl}^{-}$ion entered the interlayer space during the course of the simulation, in agreement with the modeling results of Rotenberg et al. (2007b), but in disagreement with those of Hsiao and

Table 2. Layer charge, mean $\mathrm{Na}^{+}$and $\mathrm{Cl}^{-}$concentration in the three interlayer spaces for the three systems (2WL, $3 \mathrm{WL}$, and $5 \mathrm{WL}$ ), and associated $\mathrm{NaCl}$ concentration in the bulk liquid. Interlayer ion concentrations were calculated either from our MD simulation results or by applying the MGC or MEP models with an accessible volume corresponding to the 'closest approach' hypothesis as used in Table 1 (values in parentheses correspond the value calculated with the 'Na peaks' hypothesis). All concentrations were normalized to the effective interlayer thickness corresponding to a water density of $1 \mathrm{~kg} \mathrm{dm}^{-3}$. Note that the computed surface charge was higher than the overall surface charge because no isomorphic substitution took place near the edges, meaning that the surface charge in the middle part of the layers was larger than the average charge of the layers. Values highlighted in bold were averaged over the three interlayer nanopores in each simulation. NA: Not Applicable.

\begin{tabular}{|c|c|c|c|c|c|c|c|c|}
\hline & & \multicolumn{2}{|c|}{ MD } & \multicolumn{4}{|c|}{$\begin{array}{l}\text { oncentrations in the interlayer space } \overline{\text { MEP model }} \\
\text { MGC model }\end{array}$} & \multirow{2}{*}{$\begin{array}{c}\text { Bulk } \\
\mathrm{MD} \\
\mathrm{NaCl}\end{array}$} \\
\hline & & $\mathrm{Na}^{+}$ & $\mathrm{Cl}^{-}$ & $\mathrm{Na}^{+}$ & $\mathrm{Cl}^{-}$ & $\mathrm{Na}^{+}$ & $\mathrm{Cl}^{-}$ & \\
\hline Systems & $\begin{array}{l}\text { Charge in } \\
\mathrm{C} \mathrm{m}^{-2}\end{array}$ & & \multicolumn{5}{|c|}{ - Mean concentrations in $\mathrm{mol} \mathrm{kg} \mathrm{kg}^{-1}$ - } & $\mathrm{mol} \mathrm{kg}^{-1}$ \\
\hline \multirow{4}{*}{$2 \mathrm{WL}$} & -0.11 and -0.13 & 4.1 & 0 & 4.4 (NA) & 0.014 (NA) & 4.4 (NA) & 0.006 (NA) & 0.54 \\
\hline & -0.13 and -0.16 & 4.8 & 0 & 5.4 (NA) & 0.011 (NA) & 5.3 (NA) & 0.005 (NA) & \\
\hline & -0.16 and -0.11 & 4.3 & 0 & 4.9 (NA) & 0.013 (NA) & 4.9 (NA) & 0.006 (NA) & \\
\hline & -0.13 & 4.4 & $\mathbf{0}$ & 4.9 (NA) & 0.013 (NA) & 4.9 (NA) & 0.006 (NA) & \\
\hline \multirow{4}{*}{$3 \mathrm{WL}$} & -0.09 and -0.11 & 2.2 & 0.010 & $2.4(2.4)$ & $0.044(0.013)$ & $2.3(2.3)$ & $0.041(0.012)$ & 0.44 \\
\hline & -0.11 and -0.14 & 2.9 & 0.035 & $3.0(3.0)$ & $0.036(0.010)$ & $2.9(2.9)$ & $0.033(0.010)$ & \\
\hline & -0.14 and -0.09 & 2.6 & 0.015 & $2.7(2.7)$ & $0.040(0.011)$ & $2.6(2.6)$ & $0.036(0.011)$ & \\
\hline & -0.11 & 2.6 & 0.020 & $2.7(2.7)$ & $0.040(0.011)$ & $2.6(2.6)$ & $0.037(0.011)$ & \\
\hline \multirow{4}{*}{$5 \mathrm{WL}$} & -0.11 and -0.13 & 1.5 & 0.033 & $1.6(1.6)$ & $0.046(0.026)$ & $1.6(1.6)$ & $0.039(0.024)$ & 0.30 \\
\hline & -0.13 and -0.15 & 1.9 & 0.043 & $1.8(1.8)$ & $0.042(0.024)$ & $1.8(1.8)$ & $0.035(0.021)$ & \\
\hline & -0.15 and -0.11 & 1.6 & 0.031 & $1.7(1.7)$ & $0.044(0.025)$ & $1.8(1.7)$ & $0.037(0.022)$ & \\
\hline & -0.13 & 1.7 & 0.036 & $1.7(1.7)$ & $0.044(0.025)$ & 1.7 (1.7) & $0.037(0.022)$ & 0.54 \\
\hline
\end{tabular}


Total electrostatic energy - $\mathrm{Cl}$

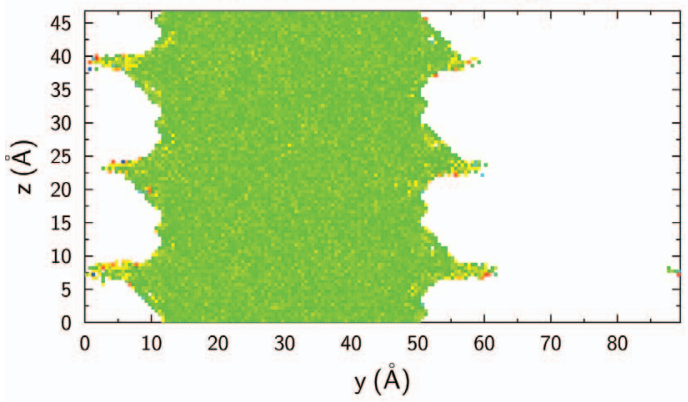

Water electrostatic energy - $\mathrm{Cl}$

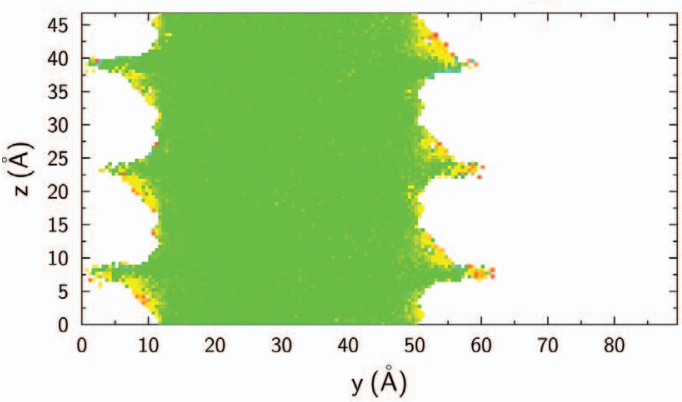

$\mathrm{NaCl}$ only $\leq 25 \AA-\mathrm{Cl}$

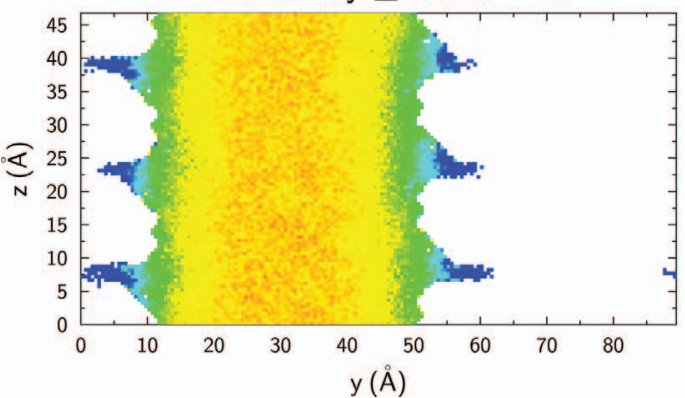

Total electrostatic energy - $\mathrm{Na}$
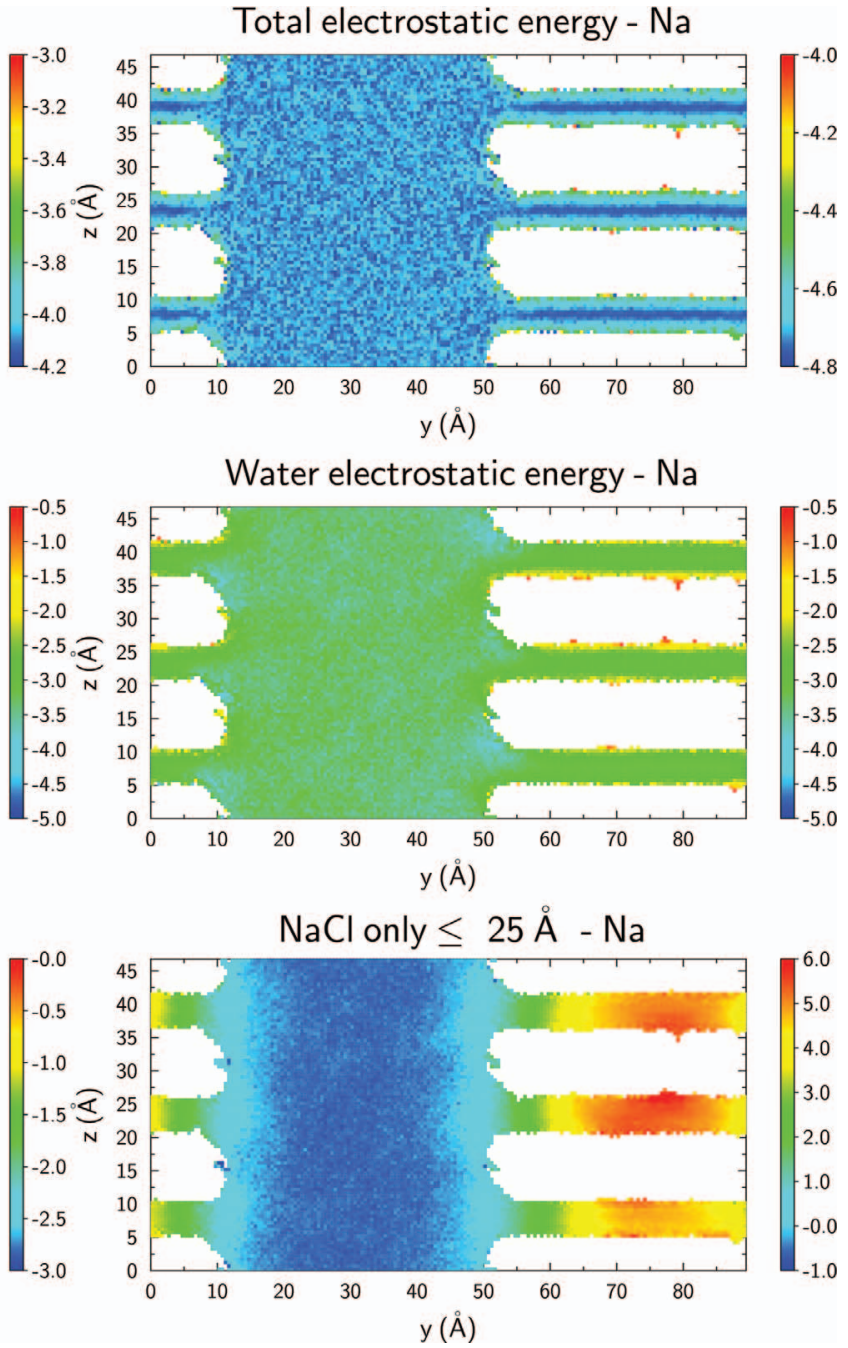

$\mathrm{NaCl}$ only $\leq 25 \AA-\mathrm{Na}$

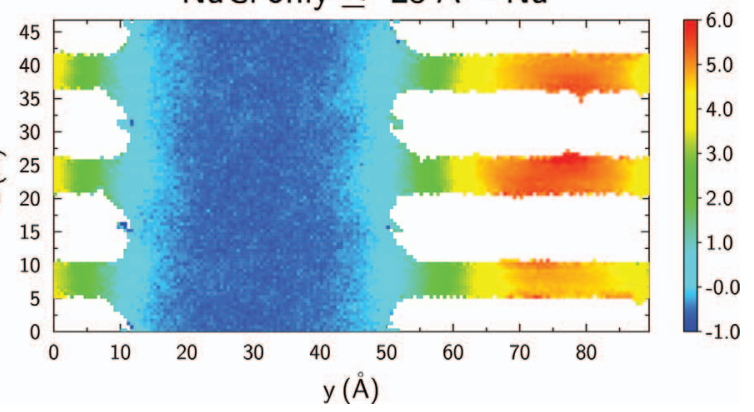

Figure 4. The $\mathrm{Cl}^{-}$(left) and $\mathrm{Na}^{+}$(right) electrostatic energy maps for the simulation period $3 \mathrm{~ns}$ to $50 \mathrm{~ns}$ in the $2 \mathrm{WL}$ system. The energy scale is in $\mathrm{eV}$. The top row shows the total electrostatic energy per ion. The middle row shows the electrostatic energy arising from interactions with water molecules. The bottom row shows the electrostatic energy arising from short-range (<25 $\AA$ ) interactions with other ions.

Hedström (2015). The $\mathrm{Cl}^{-}$concentrations expected from the energy barriers predicted by Rotenberg et al. (2007b) or Hsiao and Hedström (2015) for bulk NaCl concentrations similar to those obtained in the present study are given in Table 3 , together with the average number of $\mathrm{Cl}^{-}$ions expected in the interlayer space during the course of an entire simulation. The simulations were carried out at the same temperature $(350 \mathrm{~K})$ as the simulations of Hsiao and Hedström (2015) and with similar simulation times (50 ns vs. 100-200 ns) and volumes $\left(27 \times 10^{4} \AA^{3}\right.$ vs. $\left.15 \times 10^{4} \AA^{3}\right)$, thus ensuring roughly equally reliable output statistics. The fact that $\mathrm{Cl}^{-}$ions did not enter the interlayer space cannot, therefore, be attributed to a lack of convergence in the present simulation, as Hsiao and Hedström have postulated to explain the difference between their results and those of Rotenberg et al. (2007b).
The mapping of the per-atom electrostatic energy contributions evinced the major role played by solvation in inhibiting the entry of $\mathrm{Cl}^{-}$into the interlayer space. This effect was particularly pronounced in the $2 \mathrm{WL}$ system, perhaps because a significant fraction of the water molecules associated with the water density peaks nearest to the clay surfaces (i.e. most of the interlayer water in the $2 \mathrm{WL}$ hydrate) were engaged in solvating $\mathrm{Na}^{+}$outer-sphere surface complexes while also donating a hydrogen bond to the siloxane surface $\mathrm{O}$ atoms (Marry et al., 2008; Bourg and Sposito, 2011). In short, water located in the first monolayer on the clay surfaces had a very different structure from bulk liquid water (Low, 1979), and this difference became acute in the case of the $2 \mathrm{WL}$ hydrate. These findings are consistent with the hypothesis formulated by Hsiao and Hedstrom (2015) that differ- 

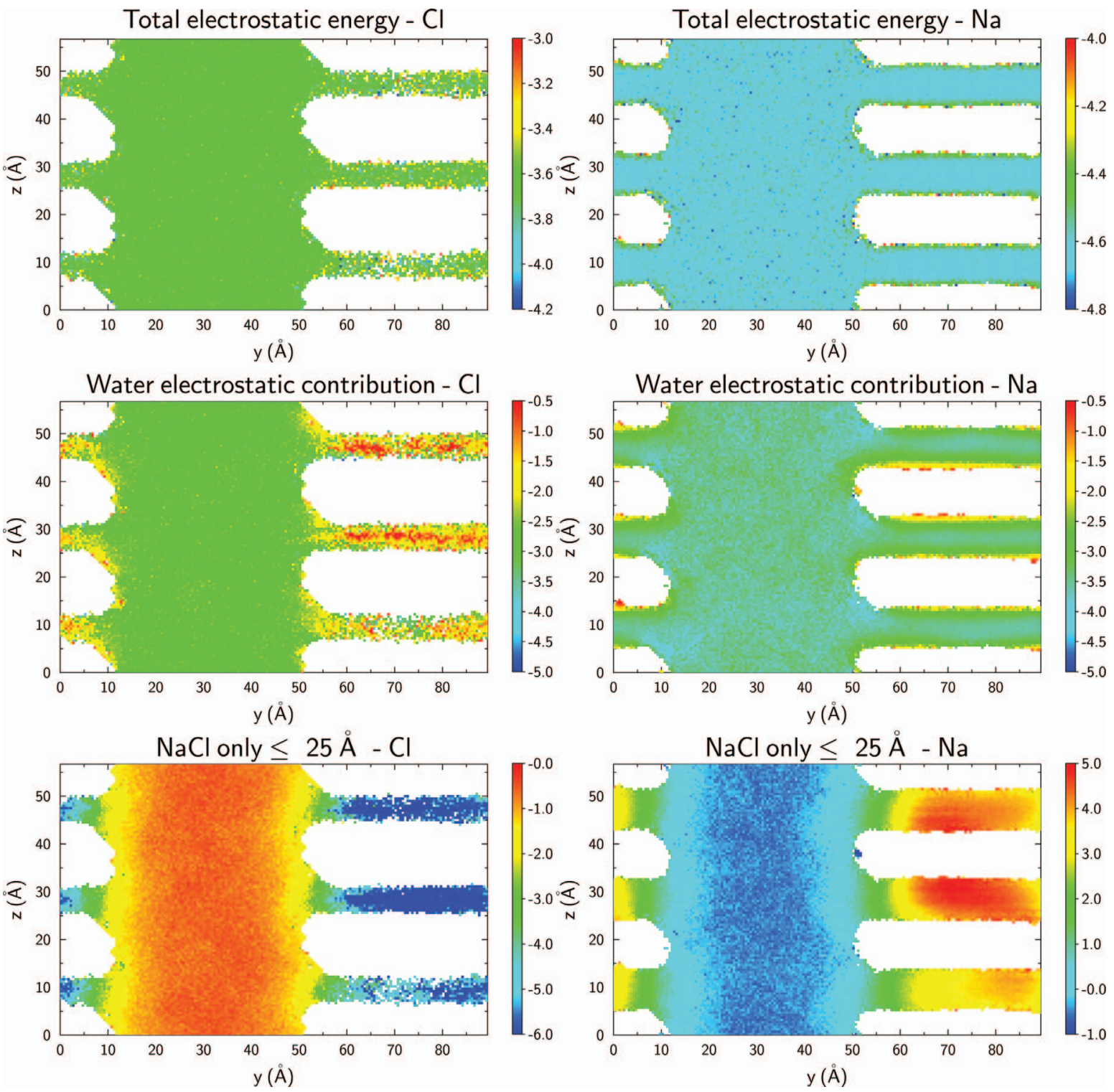

Figure 5. Same as Figure 4 for the simulation period $3 \mathrm{~ns}$ to $40 \mathrm{~ns}$ in the $3 \mathrm{WL}$ system.

Table 3. Chloride concentration expected in the 2WL hydrate interlayer space according to the energy barriers predicted by Rotenberg et al. (2007b) and Hsiao and Hedström (2015). The last column indicates the expected average number of $\mathrm{Cl}^{-}$ions in the interlayer space during the course of the entire simulation. Reported energy barriers were calculated either by umbrella sampling Rotenberg et al., (2007b) or by both umbrella sampling and unconstrained MD simulations by Hsiao and Hedström, (2015).

\begin{tabular}{lccccc}
\hline Reference & $\begin{array}{c}\text { Bulk Cl} \\
\text { concentration } \\
\left(\mathrm{mol} \mathrm{dm}^{-3}\right)\end{array}$ & $\begin{array}{c}\text { Energy } \\
\text { barrier } \\
\left(\mathrm{k}_{\mathrm{B}} \mathrm{T}\right)\end{array}$ & $\begin{array}{c}\text { Expected } \mathrm{Cl}^{-} \\
\text {interlayer concentration } \\
(\mathrm{mol} \mathrm{dm})^{-3}\end{array}$ & $\begin{array}{c}\text { Volume of one } \\
\text { interlayer space in the } \\
\text { simulations }\left(\AA^{3}\right)\end{array}$ & $\begin{array}{c}\text { Expected time-average } \\
\text { of the number of } \\
\text { interlayer } \mathrm{Cl}^{-} \text {ions in } \\
\text { the entire system }\end{array}$ \\
\hline 1. & 0.52 & $\sim 9$ & $\sim 6-7 \times 10^{-5}$ & $1.9 \times 10^{4}$ & 0.006 \\
2. & 5.2 & $3.2 \times 10^{-3}$ & & 0.33
\end{tabular}

1. Rotenberg et al. (2007b)

2. Hsiao and Hedström (2015) 
Total electrostatic energy - Cl

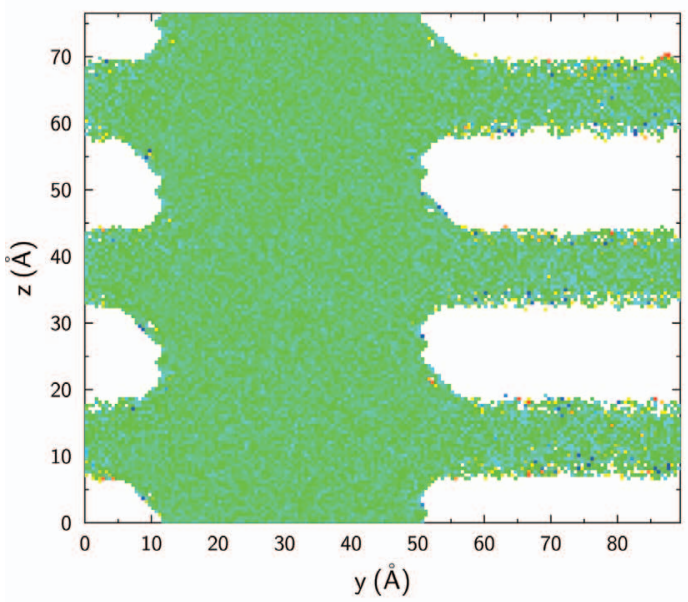

Water electrostatic contribution - $\mathrm{Cl}$

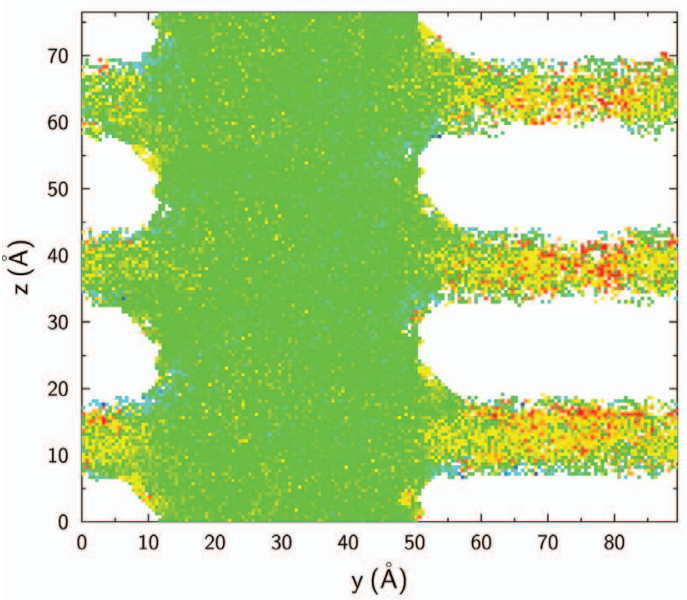

$\mathrm{NaCl}$ only $\leq 25 \AA-\mathrm{Cl}$

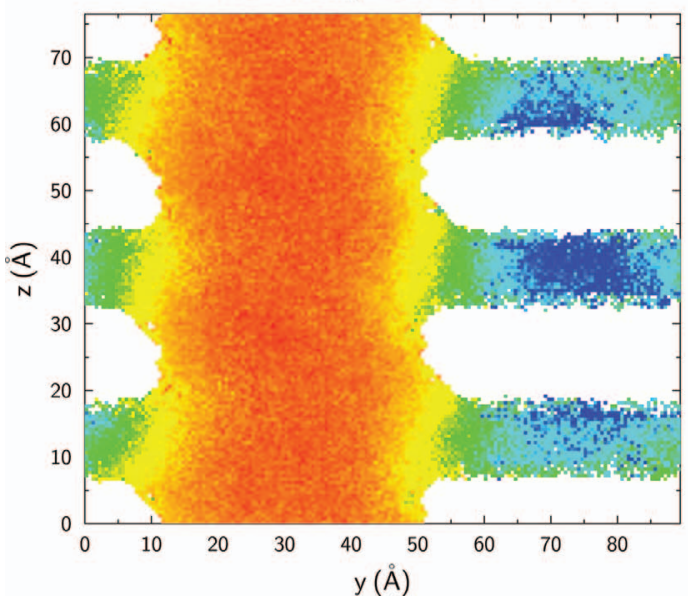

Total electrostatic energy - $\mathrm{Na}$

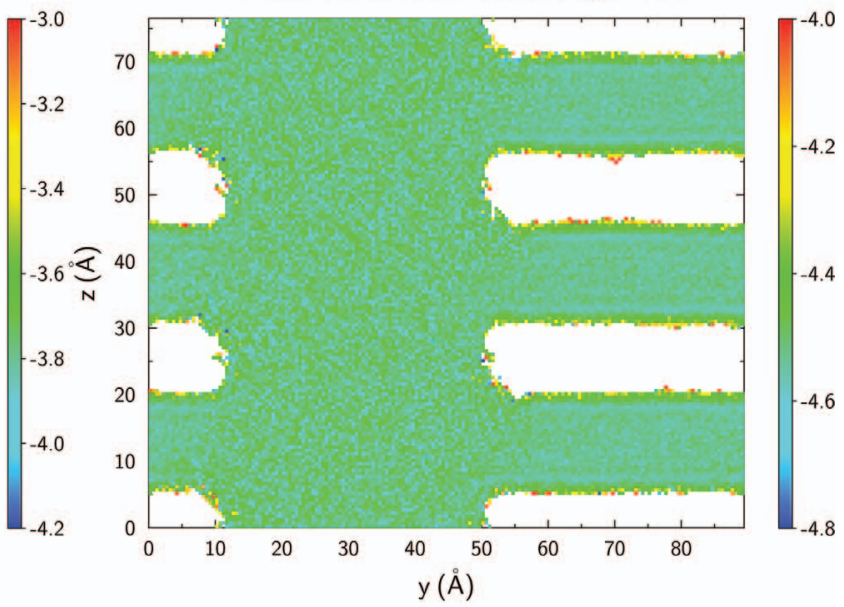

Water electrostatic contribution - $\mathrm{Na}$
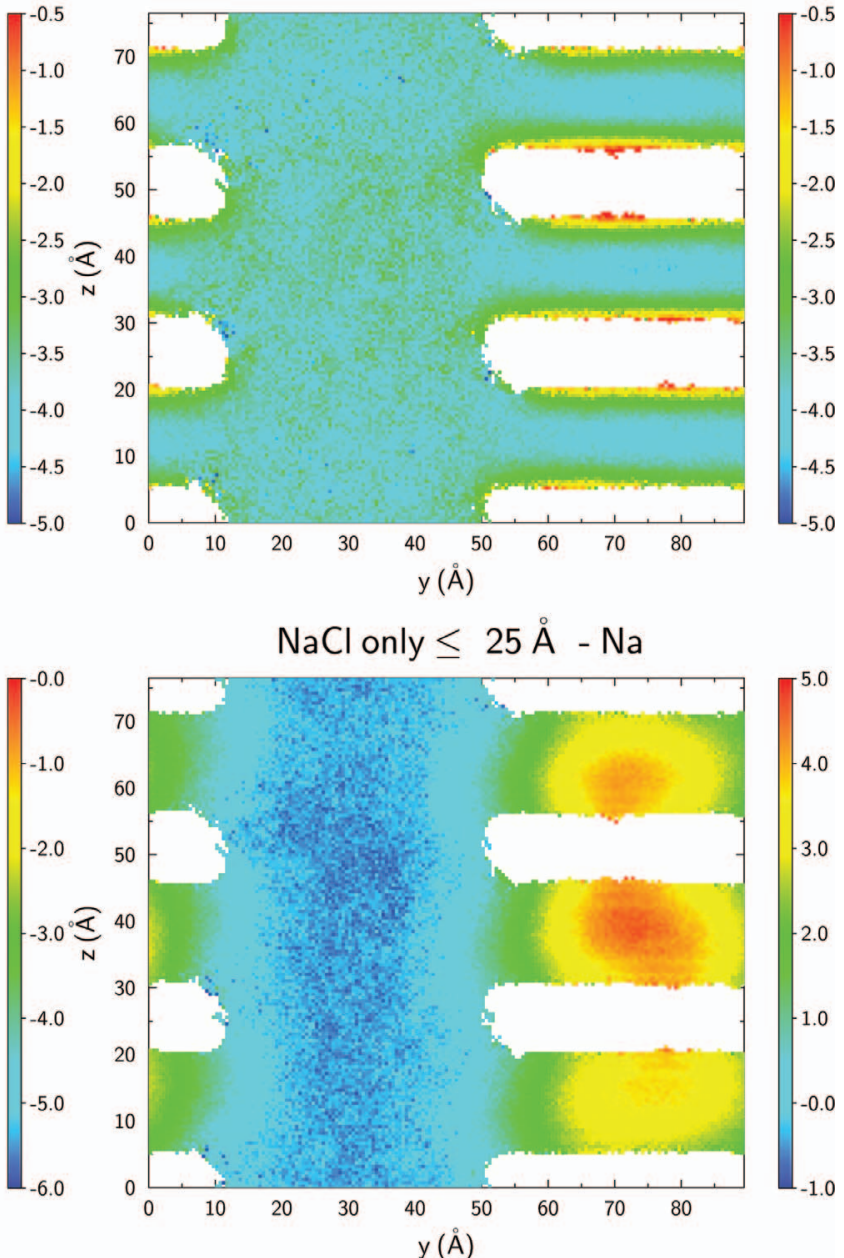

$\mathrm{NaCl}$ only $\leq 25 \AA-\mathrm{Na}$

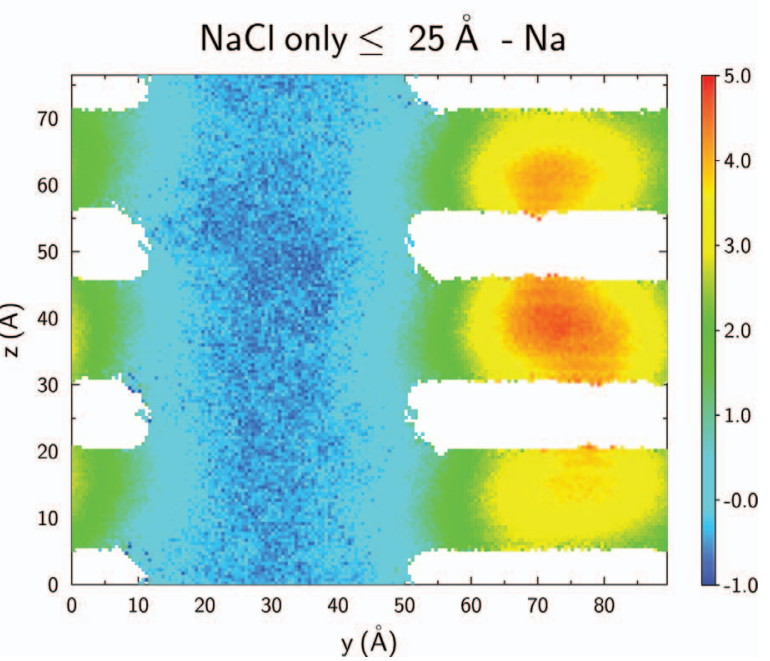

Figure 6. Same as Figure 4 for the simulation period $3 \mathrm{~ns}$ to $38 \mathrm{~ns}$ in the $5 \mathrm{WL}$ system.

ences in solvation energy play an important role in inhibiting the entry of $\mathrm{Cl}^{-}$in the interlayer space.

Molecular dynamics simulations are well known to be sensitive to the choice of parameters used to describe interatomic interactions. Consequently, differences in the extent of anion exclusion predicted by Rotenberg et al. (2007b) and Hsiao and Hedström (2015) may reflect differences in the parameterization of interatomic 
interactions in these two studies. The present work used the same interatomic potential models as Hsiao and Hedstrom (2015), namely, the CLAYFF and SPC/E models. To the best of the present authors' knowledge, the only major methodological difference between the present simulations and those of Hsiao and Hedstrom (2015) is that these latter authors treated the negative structural charge of the clay mineral particles as uniformly distributed over all octahedrally coordinated atoms in the clay mineral structure. In the present simulations, the negative charge arising from each $\mathrm{Al} \rightarrow$ $\mathrm{Mg}$ isomorphic substitution was assigned to the site of substitution and its six surrounding $\mathrm{O}$ atoms in accordance with the original CLAYFF model. The treatment of clay mineral negative structural charge used in the present study was derived from quantum mechanical calculations of the electrostatic potential near clay mineral surfaces (Cygan et al., 2004), which predicts interlayer water and ion distributions and dynamics in excellent agreement with experimental results (Bourg and Sposito, 2010; Ferrage et al., 2011; Marry et al., 2011). The present results do not allow an accurate quantification of the height of the energy barrier opposing $\mathrm{Cl}^{-}$entry into the interlayer space of the $2 \mathrm{WL}$ hydrate, but strongly suggest that this barrier is greater than that predicted by Hsiao and Hedstrom (2015).

\section{$3 W L$ and $5 W L$ hydrates}

The numerical solution of the PB equation for the $3 \mathrm{WL}$ and $5 \mathrm{WL}$ hydrates was consistent with the average interlayer $\mathrm{Na}^{+}$concentration and with the interlayer $\mathrm{Na}^{+}$ concentration profile predicted by the MD simulations (Figure 3). This close correspondence was particularly true if the distance of closest approach of ions to the clay mineral surface was identified with the foot of the $\mathrm{Cl}^{-}$ density profiles, which yields $a=2.0 \pm 0.8 \AA$. This predicted $a$ value was in good agreement with the range of values regarded as a typical ion size in studies of ion adsorption ( $a=1.8$ to $2 \AA$ ) (Sposito, 1992; Kim and Netz, 2006) and with the hydrated radii of $\mathrm{Na}^{+}$and $\mathrm{Cl}^{-}$(1.7 and $2.0 \AA$, respectively) (Jardat et al., 2009). The agreement between $\mathrm{PB}$ calculations and MD simulation predictions was somewhat worse in the case of the $\mathrm{Cl}^{-}$ concentration profiles than in the case of the $\mathrm{Na}^{+}$ profiles (Figure 3), perhaps reflecting the poorer statistics for interlayer $\mathrm{Cl}$ concentrations or the influence of short-range ion-ion interactions (and possibly ionwater interactions, as noted above) that are not accounted for in the PB equation. Nevertheless, reasonable quantitative agreement was found (Table 2). These calculations further showed that, for the systems examined, the average interlayer $\mathrm{Na}^{+}$and $\mathrm{Cl}^{-}$concentrations predicted with the MGC and MEP models were essentially identical, i.e. a full numerical resolution of the $\mathrm{PB}$ equation was not necessary to predict average ion concentrations in the nanopores. Instead, predicted interlayer anion concentrations were primarily sensitive to the distance of closest approach used in the MGC or MEP models, the best fit being obtained with a distance of closest approach intermediate between those obtained using the 'closest approach' and 'Na peaks' approximations. The similarity of the MGC and MEP models in the case of monovalent ions is consistent with recent predictions of the density profiles of $\mathrm{Na}^{+}, \mathrm{Cl}^{-}$, and $\mathrm{Br}^{-}$(but not $\mathrm{Ca}^{2+}$ ) in a $31.5 \AA$-wide clay interlayer nanopore (Tinnacher et al., 2016).

According to Hsiao and Hedstrom (2015), solving the Poisson-Boltzmann equation in order to model the behavior of ions in clayey media is not necessary, because the use of the Donnan equilibrium (DE) model is warranted for compacted clay systems. A strict application of Henry's Law (and, hence, of the DE model) to clay systems would require that the counterions be dissociated fully from the mineral surface, such that mean ionic concentrations in the hydrated clay phase be unambiguously determined (Babcock, 1963). The present MD simulations were carried out at a relatively high salinity and, therefore, the simulations cannot determine whether Henry's Law is valid for counter-ions in a clay system. However, MGC model calculations (Sposito, 1992), X-ray reflectivity experiments (Schlegel et al., 2006; Lee et al., 2010, 2012), and MD simulation studies (Marry et al., 2002; Rotenberg et al., 2007a; Holmboe and Bourg, 2014) have provided strong evidence that cations remain condensed at clay mineral-water and mica-water interfaces, even under bulk solution conditions approaching infinite dilution. The results presented here indicate MGC model calculations and MD simulations are mutually consistent, even in highly compacted clays, and, therefore, suggest that the DE model cannot be valid, even in highly compacted clay.

The PB model does not rely on the validity of Henry's Law. Consequently, the MEP model predictions are similar to those of the DE model and it remains valid within the limits of the underlying molecular-scale hypotheses and approximations. The interlayer pore scale of the $3 \mathrm{WL}$ system can be considered as the lower limit for water content in this model. Below this scale, the mean force potential that applies to $\mathrm{Cl}^{-}$ions entering the interlayer region cannot be approximated using mean field theories, because $\mathrm{Cl}^{-}$is significantly more weakly solvated by confined water than by bulk liquid water. Within the context of the MEP (or MGC) model, this effect can be modeled in a straightforward manner by accounting for the distance of closest approach of ions to the clay surface, $a \sim 2 \AA$.

\section{CONCLUSIONS}

The present MD simulations demonstrated that anion exclusion from clay interlayer nanopores is significantly greater than expected from mean field theories, such as 
the modified Gouy-Chapman (MGC) or the simplified mean electrostatic potential (MEP) models. The calculations showed that this effect can be viewed as arising from the weaker solvation of $\mathrm{Cl}^{-}$by confined water than by bulk liquid water and it can be modeled by accounting for the closest approach distance of ions to the clay surface, $a \sim 2 \AA$. Calculations reported here further suggest the existence of a threshold value in nanopore width below which $\mathrm{Cl}^{-}$cannot readily access clay interlayer nanopores.

Comparison of the MD simulation results with the underlying hypothesis of the Donnan model established that the Donnan model cannot be applied to clay-water mixtures because these systems do not satisfy the two basic assumptions made about the behavior of ions in a Donnan system. This problem is related to the geometry of the charged surfaces (infinite plane), which leads to counterion condensation in the vicinity of the surface (Sposito, 1992), thereby preventing the full dissociation of $\mathrm{Na}^{+}$ions from the surface at infinite dilution required by the Donnan model. Although a mean electrostatic potential model derived from the Poisson-Boltzmann equation may be equivalent numerically to the Donnan model, it is fundamentally different in terms of the underlying hypotheses.

The ability of $\mathrm{Cl}^{-}$to enter clay interlayer nanopores decreases sharply as pore size decreases from $9.1 \AA$ (3WL hydrate) to $5.7 \AA$ (2WL hydrate). This finding should be taken into account when predicting the membrane properties of compacted clay materials. The present results suggest that clay materials may behave as nearly ideal semi-permeable membranes under conditions where only $2 \mathrm{WL}$ interlayer spaces (or inter-particle pores of similar width) connect the diffusion paths between larger pores, in agreement with recent experimental results by Chagneau et al. (2015).

\section{ACKNOWLEDGMENTS}

This work was supported by the Director, Office of Science, Office of Basic Energy Sciences, Chemical Sciences, Geosciences, and Biosciences Division, of the U.S. Department of Energy under Contract DE-AC0205CH11231. C. Tournassat acknowledges funding from L'Institut Carnot BRGM for his visit to the Lawrence Berkeley National Laboratory, and from the CNRS-NEEDS project TRANSREAC. G. Sposito acknowledges funding from the University of California at Berkeley under the auspices of a Chancellor's Professorship. The research reported in this paper used resources of the National Energy Research Scientific Computing Center (NERSC), which is supported by the Office of Science of the U.S. Department of Energy under Contract DE-AC-02$05 \mathrm{CH} 11231$.

\section{REFERENCES}

Altmann, S. (2008) Geo'chemical research: A key building block for nuclear waste disposal safety cases. Journal of Contaminant Hydrology, 102, 174-179.

Altmann, S., Tournassat, C., Goutelard, F., Parneix, J.-C.,
Gimmi, T., and Maes, N. (2012) Diffusion-driven transport in clayrock formations. Applied Geochemistry, 27, $463-478$.

Appelo, C.A.J. and Wersin, P. (2007) Multicomponent diffusion modeling in clay systems with application to the diffusion of tritium, iodide, and sodium in Opalinus clay. Environmental Science \& Technology, 41, 5002-5007.

Appelo, C.A.J., Van Loon, L.R., and Wersin, P. (2010) Multicomponent diffusion of a suite of tracers (HTO, Cl, $\mathrm{Br}, \mathrm{I}, \mathrm{Na}, \mathrm{Sr}, \mathrm{Cs}$ ) in a single sample of Opalinus clay. Geochimica et Cosmochimica Acta, 74, 1201-1219.

Babcock, K.L. (1960) Some characteristics of a model Donnan system. Soil Science, 90, 245-252.

Babcock, K.L. (1963) Theory of the chemical properties of soil colloidal systems at equilibrium. Hilgardia, 34, 417-542.

Berendsen, H.J.C., Grigera, J.R., and Straatsma, T.P. (1987) The missing term in effective pair potentials. Journal of Physical Chemistry, 91, 6269-6271.

Bickmore, B.R., Rosso, K.M., Nagy, K.L., Cygan, R.T., and Tadanier, C.J. (2003) Ab initio determination of edge surface structures for dioctahedral 2: 1 phyllosilicates: Implications for acid-base reactivity. Clays and Clay Minerals, 51, 359-371.

Birgersson, M. and Karnland, O. (2009) Ion equilibrium between montmorillonite interlayer space and an external solution-Consequences for diffusional transport. Geochimica et Cosmochimica Acta, 73, 1908-1923.

Bocquet, L. and Charlaix, E. (2010) Nanofluidics, from bulk to interfaces. Chemical Society Reviews, 39, 1073-1095.

Bourg, I.C. and Sposito, G. (2010) Connecting the molecular scale to the continuum scale for diffusion processes in smectite-rich porous media. Environmental Science \& Technology, 44, 2085-2091.

Bourg, I.C. and Sposito, G. (2011) Molecular dynamics simulations of the electrical double layer on smectite surfaces contacting concentrated mixed electrolyte ( $\mathrm{NaCl}-$ $\mathrm{CaCl}_{2}$ ) solutions. Journal of Colloid and Interface Science, 360, $701-715$.

Bourg, I.C. and Tournassat, C. (2015) Self-diffusion of water and ions in clay barriers. Ch. 6 pp. $71-100$ in: Natural and Engineered Clay Barriers (C. Tournassat, C.I. Steefel, I.C. Bourg, and F. Bergaya, editors). Developments in Clay Science, 6. Elsevier.

Bourg, I.C., Sposito, G., and Bourg, A.C.M. (2008) Modeling the diffusion of $\mathrm{Na}^{+}$in compacted water-saturated Nabentonite as a function of pore water ionic strength. Applied Geochemistry, 23, 3635-3641.

Chagneau, A., Tournassat, C., Steefel, C.I., Bourg, I.C., Kupcik, T., Gaboreau, S., Claret, F., Esteve, I., and Schäfer, T. (2015) Complete restriction of ${ }^{36} \mathrm{Cl}^{-}$diffusion by celestite precipitation in densely compacted illite. Environmental Science \& Technology Letters, 2, 139-143.

Cheng, G. and Hendry, M.J. (2014) Chemico-osmosis in geologic membranes: Role of membrane potential gradient. Geochimica et Cosmochimica Acta, 141, 270-280.

Churakov, S.V. (2006) Ab initio study of sorption on pyrophyllite: Structure and acidity of the edge sites. The Journal of Physical Chemistry B, 110, 4135-4146.

Churakov, S.V. and Gimmi, T. (2011) Up-scaling of molecular diffusion coefficients in clays: A two-step approach. The Journal of Physical Chemistry C, 115, 6703-6714.

Claret, F., Lerouge, C., Laurioux, T., Bizi, M., Conte, T., Ghestem, J.P., Wille, G., Sato, T., Gaucher, E.C., Giffaut, E., and Tournassat, C. (2010) Natural iodine in a clay formation: Implications for iodine fate in geological disposals. Geochimica et Cosmochimica Acta, 74, 16-29.

Crozier, P.S., Henderson, D., Rowley, R.L., and Busath, D.D. (2001) Model channel ion currents in NaCl-extended simple point charge water solution with applied-field molecular 
dynamics. Biophysical journal, 81, 3077-3089.

Cygan, R.T., Liang, J.-J., and Kalinichev, A.G. (2004) Molecular models of hydroxide, oxyhydroxide, and clay phases and the development of a general force field. The Journal of Physical Chemistry B, 108, 1255-1266.

Eastwood, J., Hockney, R., and Lawrence, D. (1980) P3M3DP - The three-dimensional periodic particle-particle/particlemesh program. Computer Physics Communications, 19, $215-261$.

Ferrage, E., Sakharov, B.A., Michot, L.J., Delville, A., Bauer, A., Lanson, B., Grangeon, S., Frapper, G., Jiménez-Ruiz, M., and Cuello, G.J. (2011) Hydration properties and interlayer organization of water and ions in synthetic Nasmectite with tetrahedral layer charge. Part 2. Toward a precise coupling between molecular simulations and diffraction data. The Journal of Physical Chemistry C, 115, $1867-1881$.

Fritz, S.J. (1986) Ideality of clay membranes in osmotic processes: a review. Clays and Clay Minerals, 34, 214-223.

Glaus, M.A., Frick, S., Rossé, R., and Van Loon, L.R. (2011) Consistent interpretation of the results of through-, outdiffusion and tracer profile analysis for trace anion diffusion in compacted montmorillonite. Journal of Contaminant Hydrology, 123, 1-10.

Glaus, M.A., Birgersson, M., Karnland, O., and Van Loon, L.R. (2013) Seeming steady-state uphill diffusion of ${ }^{22} \mathrm{Na}^{+}$ in compacted montmorillonite. Environmental Science \& Technology, 47, 11522-11527.

Hedström, M. and Karnland, O. (2012) Donnan equilibrium in Na-montmorillonite from a molecular dynamics perspective. Geochimica et Cosmochimica Acta, 77, 266-274.

Holmboe, M. and Bourg, I.C. (2014) Molecular dynamics simulations of water and sodium diffusion in smectite interlayer nanopores as a function of pore size and temperature. The Journal of Physical Chemistry C, 118, $1001-1013$.

Holmboe, M., Wold, S., and Jonsson, M. (2012) Porosity investigation of compacted bentonite using XRD profile modeling. Journal of Contaminant Hydrology, 128, 19-32.

Hsiao, Y.-W. and Hedström, M. (2015) Molecular dynamics simulations of $\mathrm{NaCl}$ permeation in bihydrated montmorillonite interlayer nanopores. The Journal of Physical Chemistry C, 119, 17352-17361.

Isele-Holder, R.E., Mitchell, W., and Ismail, A.E. (2012) Development and application of a particle-particle particlemesh Ewald method for dispersion interactions. The Journal of Chemical Physics, 137, 174107-174107.

Jardat, M., Dufreche, J.F., Marry, V., Rotenberg, B., and Turq, P. (2009) Salt exclusion in charged porous media: a coarsegraining strategy in the case of montmorillonite clays. Physical Chemistry Chemical Physics, 11, 2023-2033.

Keijzer, T.J., Kleingeld, P., and Loch, J. (1999) Chemical osmosis in compacted clayey material and the prediction of water transport. Engineering Geology, 53, 151-159.

Kharaka, Y.K. and Berry, F.A. (1973) Simultaneous flow of water and solutes through geological membranes I. Experimental investigation. Geochimica et Cosmochimica Acta, 37, 2577-2603.

Kim, Y.W. and Netz, R.R. (2006) Electro-osmosis at inhomogeneous charged surfaces: Hydrodynamic versus electric friction. The Journal of Chemical Physics, 124, 114709.

Kraepiel, A.M.L., Keller, K., and Morel, F.M.M. (1999) A model for metal adsorption on montmorillonite. Journal of Colloid and Interface Science, 210, 43-54.

Lee, S.S., Fenter, P., Park, C., Sturchio, N.C., and Nagy, K.L. (2010) Hydrated Cation Speciation at the Muscovite (001)Water Interface. Langmuir, 26, 16647-16651.

Lee, S.S., Fenter, P., Nagy, K.L., and Sturchio, N.C. (2012) Monovalent ion adsorption at the muscovite $(001)$-solution interface: Relationships among ion coverage and speciation, interfacial water structure, and substrate relaxation. Langmuir, 28, 8637-8650.

Leroy, P., Revil, A., and Coelho, D. (2006) Diffusion of ionic species in bentonite. Journal of Colloid and Interface Science, 296, 248-255.

Liu, X., Cheng, J., Sprik, M., Lu, X., and Wang, R. (2014) Surface acidity of 2:1-type dioctahedral clay minerals from first principles molecular dynamics simulations. Geochimica et Cosmochimica Acta, 140, 410-417.

Low, P.F. (1979) Nature and properties of water in montmorillonite-water systems. Soil Science Society of America Journal, 43, 651-658.

Marry, V., Turq, P., Cartailler, T., and Levesque, D. (2002) Microscopic simulation for structure and dynamics of water and counterions in a monohydrated montmorillonite. The Journal of Chemical Physics, 117, 3454-3463.

Marry, V., Rotenberg, B., and Turq, P. (2008) Structure and dynamics of water at a clay surface from molecular dynamics simulation. Physical Chemistry Chemical Physics, 10, 4802-4813.

Marry, V., Dubois, E., Malikova, N., Durand-Vidal, S., Longeville, S., and Breu, J. (2011) Water dynamics in hectorite clays: Infuence of temperature studied by coupling neutron spin echo and molecular dynamics. Environmental Science \& Technology, 45, 2850-2855.

Muurinen, A., Karnland, O., and Lehikoinen, J. (2007) Effect of homogenization on the microstructure and exclusion of chloride in compacted bentonite. Physics and Chemistry of the Earth, Parts $A / B / C, 32,485-490$.

Newton, A.G. and Sposito, G. (2015) Molecular dynamics simulations of pyrophyllite edge surfaces: structure, surface energies, and solvent accessibility. Clays and Clay Minerals, 63, 277-289.

Newton, A.G., Kwon, K.D., and Cheong, D.-K. (2016) Edge structure of montmorillonite from atomistic simulations. Minerals, 6, 25.

Nikaido, H. (2003) Molecular basis of bacterial outer membrane permeability revisited. Microbiology and Molecular Biology Reviews, 67, 593-656.

Nikaido, H. and Rosenberg, E.Y. (1981) Effect on solute size on diffusion rates through the transmembrane pores of the outer membrane of Escherichia coli. The Journal of General Physiology, 77, 121-135.

Plimpton, S. (1995) Fast parallel algorithms for short-range molecular dynamics. Journal of Computational Physics, 117, $1-19$.

Revil, A., Woodruff, W., and Lu, N. (2011) Constitutive equations for coupled flows in clay materials. Water Resources Research, 47, 1-21.

Richards, L.A., Schäfer, A.I., Richards, B.S., and Corry, B. (2012) The importance of dehydration in determining ion transport in narrow pores. Small, 8, 1701-1709.

Rotenberg, B., Marry, V., Dufreche, J.-F., Malikova, N., Giffaut, E., and Turq, P. (2007a) Modelling water and ion diffusion in clays: A multiscale approach. Comptes Rendus Chimie, 10, 1108-1116.

Rotenberg, B., Marry, V., Vuilleumier, R., Malikova, N., Simon, C., and Turq, P. (2007b) Water and ions in clays: Unraveling the interlayer/micropore exchange using molecular dynamics. Geochimica et Cosmochimica Acta, 71, $5089-5101$

Ryckaert, J.-P., Ciccotti, G., and Berendsen, H.J.C. (1977) Numerical integration of the cartesian equations of motion of a system with constraints: molecular dynamics of $n$ alkanes. Journal of Computational Physics, 23, 327-341.

Schlegel, M.L., Nagy, K.L., Fenter, P., Cheng, L., Sturchio, N.C., and Jacobsen, S.D. (2006) Cation sorption on the muscovite $\left(\begin{array}{lll}0 & 0 & 1\end{array}\right)$ surface in chloride solutions using high- 
resolution X-ray reflectivity. Geochimica et Cosmochimica Acta, 70, 3549-3565.

Schoch, R.B., Han, J., and Renaud, P. (2008) Transport phenomena in nanofluidics. Reviews of Modern Physics, 80, 839 .

Sherwood, J. and Craster, B. (2000) Transport of water and ions through a clay membrane. Journal of Colloid and Interface Science, 230, 349-358.

Smith, D., Pivonka, P., Jungnickel, C., and Fityus, S. (2004) Theoretical analysis of anion exclusion and diffusive transport through platy-clay soils. Transport in Porous Media, 57, 251-277.

Smith, D.E. and Dang, L.X. (1994) Computer simulations of $\mathrm{NaCl}$ association in polarizable water. The Journal of Chemical Physics, 100, 3757-3766.

Sposito, G. (1984) The Surface Chemistry of Soils. Oxford University Press, New York.

Sposito, G. (1992) The diffuse-ion swarm near smectite particles suspended in 1:1 electrolyte solutions: modified Gouy-Chapman theory and quasicrystal formation. Pp. 127-156 in: Clay-Water Interface and its Rheological Implications (N. Güven and R.M. Pollastro, editors). The Clay Minerals Society, Boulder, Colorado, USA.

Sposito, G. (2004) The Surface Chemistry of Natural Particles. Oxford University Press, New York.

Tachi, Y., Yotsuji, K., Suyama, T., and Ochs, M. (2014) Integrated sorption and diffusion model for bentonite. Part 2: porewater chemistry, sorption and diffusion modeling in compacted systems. Journal of Nuclear Science and Technology, 51, 1-14.

Tambach, T.J., Hensen, E.J.M., and Smit, B. (2004) Molecular simulations of swelling clay minerals. The Journal of Physical Chemistry B, 108, 7586-7596.

Tertre, E., Ferrage, E., Bihannic, I., Michot, L.J., and Pret, D. (2011) Influence of the ionic strength and solid/solution ratio on $\mathrm{Ca}(\mathrm{II})-$ for- $\mathrm{Na}(+)$ exchange on montmorillonite. Part 2: Understanding the effect of the $\mathrm{m} / \mathrm{V}$ ratio. Implications for pore water composition and element transport in natural media. Journal of Colloid and Interface Science, 363, 334-347.

Tinnacher, R.M., Holmboe, M., Tournassat, C., Bourg, I.C., and Davis, J.A. (2016) Ion adsorption and diffusion in smectite: molecular, pore, and continuum scale views. Geochimica et Cosmochimica Acta, 177, 130-149.

Tournassat, C. and Appelo, C.A.J. (2011) Modelling approaches for anion-exclusion in compacted $\mathrm{Na}$-bentonite. Geochimica et Cosmochimica Acta, 75, 3698-3710.

Tournassat, C., Gaucher, E.C., Fattahi, M., and Grambow, B. (2007) On the mobility and potential retention of iodine in the Callovian-Oxfordian formation. Physics and Chemistry of the Earth, 32, 539-551.

Tournassat, C., Chapron, Y., Leroy, P., and Boulahya, F. (2009) Comparison of molecular dynamics simulations with Triple Layer and modified Gouy-Chapman models in a $0.1 \mathrm{M} \mathrm{NaCl}$-montmorillonite system. Journal of Colloid and Interface Science, 339, 533-541.

Tournassat, C., Bizi, M., Braibant, G., and Crouzet, C. (2011) Influence of montmorillonite tactoid size on $\mathrm{Na}-\mathrm{Ca}$ cation exchange reactions. Journal of Colloid and Interface Science, 364, 443-454.

Tournassat, C., Gaboreau, S., Robinet, J.-C., Bourg, I.C., and Steefel, C.I. (2016) Impact of microstructure on anion exclusion in compacted clay media. Ch. 11, pp. 137-149 in: CMS Workshop Lecture Series, Vol. 21. The Clay Minerals Society, Boulder, Colorado, USA.

Tsipursky, S.I. and Drits, V.A. (1984) The distribution of octahedral cations in the 2:1 layers of dioctahedral smectites studied by oblique-texture electron diffraction. Clay Minerals, 19, 177-193.

Wang, X.-L., Tsuru, T., Nakao, S., and Kimura, S. (1995) Electrolyte transport through nanofiltration membranes by the space-charge model and the comparison with TeorellMeyer-Sievers model. Journal of Membrane Science, 103, $117-133$.

Wersin, P., Curti, E., and Appelo, C.A.J. (2004) Modelling bentonite-water interactions at high solid/liquid ratios: swelling and diffuse double layer effects. Applied Clay Science, 26, 249-257.

White, G.N. and Zelazny, L.W. (1988) Analysis and implications of the edge structure of dioctahedral phyllosilicates. Clays and Clay Minerals, 36, 141-146.

(Received 12 November 2015; revised 21 April 2016; Ms. 1067; AE: A.G. Kalinichev) 